Elsevier required licence: (C) <2021>. This manuscript version is made available under the CC-BY-NCND 4.0 license http://creativecommons.org/licenses/by-nc-nd/4.0/

The definitive publisher version is available online at

[https://www.sciencedirect.com/science/article/pii/S0341816221000060?via\%3Dihub] 
Elsevier Editorial system(tm) for Catena Manuscript Draft

\author{
Manuscript Number: CATENA11686R2
}

Title: Usage of antecedent soil moisture for improving the performance of rainfall thresholds for landslide early warning

Article Type: Research Paper

Keywords: landslides; rainfall thresholds; LEWS; soil moisture; Idukki

Corresponding Author: Professor Biswajeet Pradhan, PhD

Corresponding Author's Institution: University of Technology Sydney

First Author: Minu Treesa Abraham, Ph.D.,

Order of Authors: Minu Treesa Abraham, Ph.D.,; Neelima Satyam, Ph.D.,; Ascanio Rosi, Ph.D., ; Biswajeet Pradhan, PhD; Samuele Segoni, Ph.D.,

Abstract: Landslides triggered by heavy rains are increasing in number and creating severe losses in hilly regions across the world. Rainfall thresholds on regional and local-scales are being used for forecasting such events, for efficient early warning. Empirical and probabilistic approaches for defining rainfall thresholds are traditional tools which are being used as part of the forecasting system for rainfall induced landslides. Such methods are easy-to-use and are based on statistical analyses. They can be derived without looking into the complex hydrogeological processes involved in slope failures, but are often associated with the disadvantage of higher false alarms, limiting their applications in a regional landslide early warning system (LEWS). This study is an attempt to improve the performance of conventional meteorological thresholds by considering the effect of soil moisture, using a probabilistic approach. Idukki district in southern part of India is highly susceptible to landslides and has witnessed major socio-economical setbacks in the recent disasters happened in 2018 and 2019. This tourist hub is now in need of a landslide forecasting system, which can help in landslide risk reduction. This study attempts to understand the effect of averaged soil moisture estimates derived from passive microwave remote sensing data, for improving the performance of conventional empirical and probabilistic thresholds. For defining empirical thresholds, an algorithm-based approach such as Calculation of Thresholds for Rainfallinduced Landslides Tool (CTRL-T) has been used. Probabilistic thresholds were defined using a Bayesian approach, finding the posterior probability of occurrence using the marginal and conditional probabilities of the control parameters along with the prior probability of occurrence of landslide. The derived rainfall thresholds were quantitatively compared with the Bayesian probabilistic threshold derived using rainfall severity and soil wetness using an area under the curve (AUC) based receiver operating characteristics (ROC) curve method. The results show that when the antecedent moisture content in soil is less, only severe rainfall events can trigger landslides in the study area; while less severe rainfall events can also trigger landslides when the soil is wet. The role of soil wetness in the initiation is used to improve the performance of the conventional methods, and a ROC approach was used for the statistical comparison of different models. Further, the results 
indicated that the probabilistic threshold using rainfall severity and soil wetness outperformed the conventional approaches with AUC of 0.96, being the most sensitive and specific among the models considered. This result opens new promising perspectives for the development of an operational LEWS in the Idukki district based on a combination of rainfall and soil moisture data. Moreover, this work contributes to strengthen the advancing trend of hydro-meteorological thresholds based on soil moisture, which is gaining a growing attention in landslide studies and that, to date, was lacking evidences in monsoon regions. 

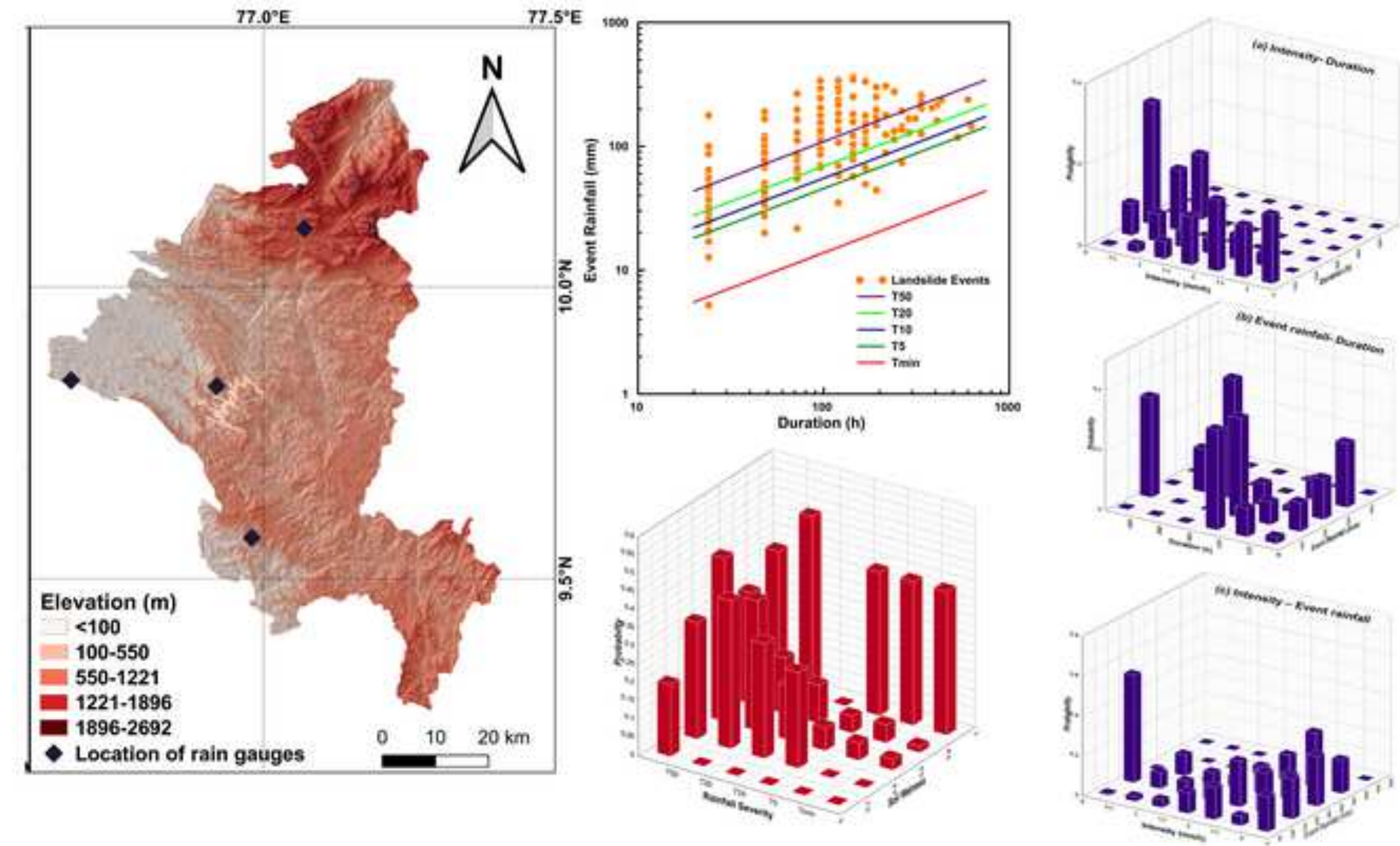

\section{Graphical Abstract}

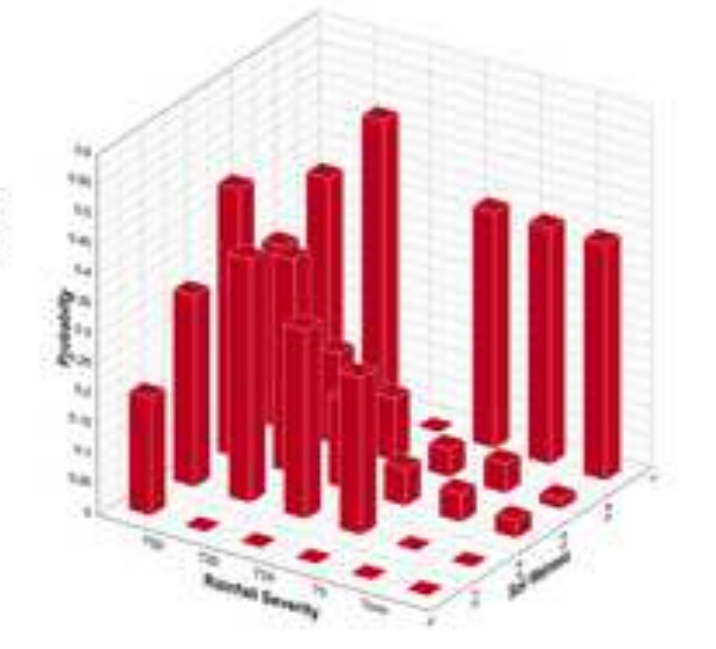

Isiijpla 


\section{Highlights}

- Landslides can be predicted using empirical and probabilistic rainfall thresholds.

- Soil moisture is critical in slope stability as it affects the infiltration rate.

- Soil moisture can be used with conventional thresholds for better performance.

- Idukki (India) is highly a highly susceptible landslide zone in the Western Ghats.

- Critical rainfall conditions, considering the soil wetness are derived for Idukki. 
.

\title{
Usage of antecedent soil moisture for improving the performance of rainfall
}

\author{
thresholds for landslide early warning
}

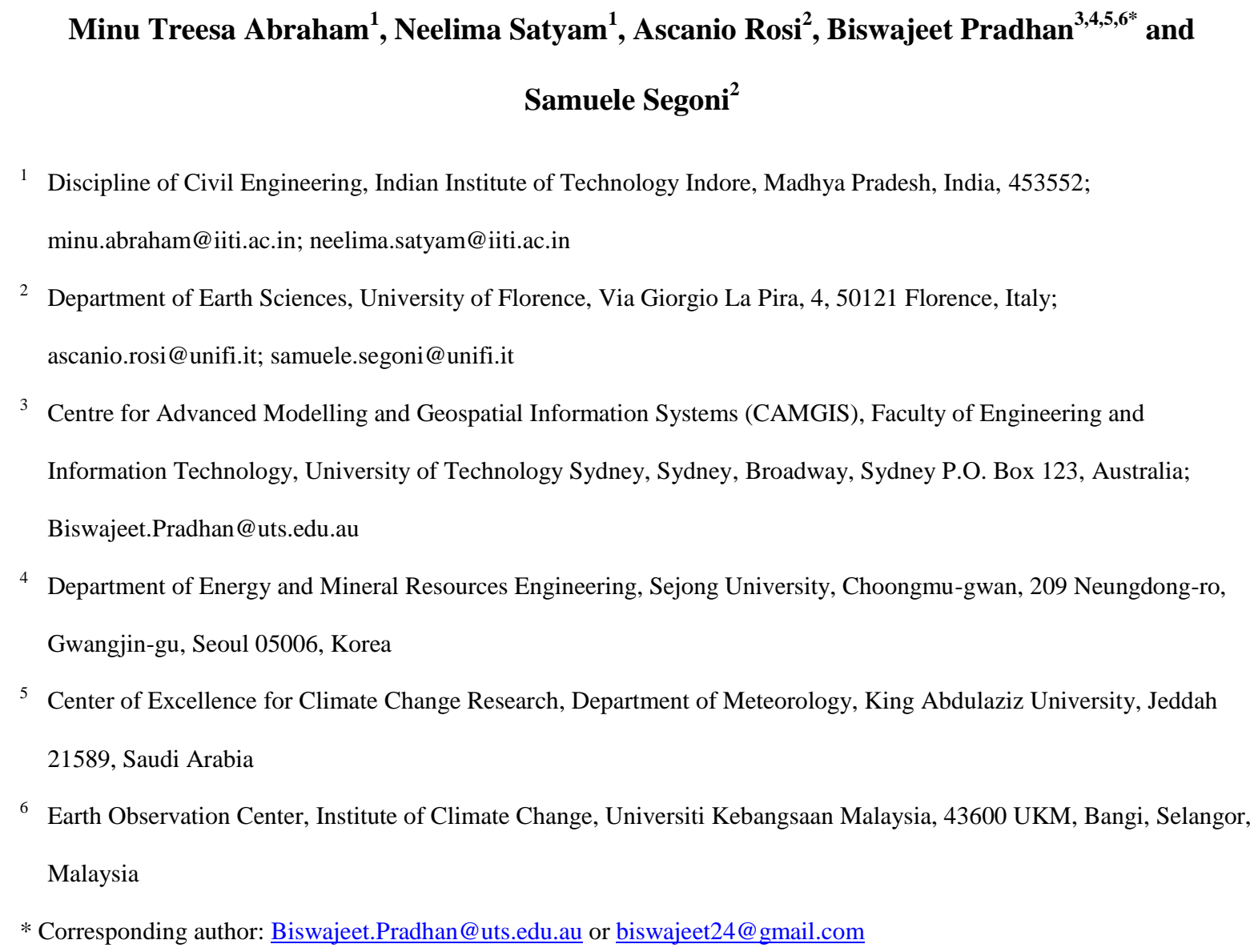

\section{Abstract}

Landslides triggered by heavy rains are increasing in number and creating severe losses in hilly regions across the world. Rainfall thresholds on regional and local-scales are being used for forecasting such events, for efficient early warning. Empirical and probabilistic approaches for defining rainfall thresholds are traditional tools which are being used as part of the landslide forecasting system for rainfall induced landslides. Such methods are easy-to-use and are based on statistical analyses. They can be derived without looking into the complex hydro-geological processes involved in slope failures, but are often associated with the disadvantage of higher false alarms, 
limiting their applications in a regional landslide early warning system (LEWS). This study is an attempt to improve the performance of conventional meteorological thresholds by considering the effect of soil moisture, using a probabilistic approach. Idukki district in southern part of India is highly susceptible to landslides and has witnessed major socio-economical setbacks in the recent disasters happened in 2018 and 2019. This tourist hub is now in need of a landslide forecasting system, which can help in landslide risk reduction. This study attempts to understand the effect of averaged soil moisture estimates derived from passive microwave remote sensing data, for improving the performance of conventional empirical and probabilistic thresholds. For defining empirical thresholds, an algorithm-based approach such as Calculation of Thresholds for Rainfall-induced Landslides Tool (CTRL-T) has been used. Probabilistic thresholds were defined using a Bayesian approach, finding the posterior probability of occurrence using the marginal and conditional probabilities of the control parameters along with the prior probability of occurrence of landslide. The derived rainfall thresholds were quantitatively compared with the Bayesian probabilistic threshold derived using rainfall severity and soil wetness using an area under the curve (AUC) based receiver operating characteristics (ROC) curve method. The results show that when the antecedent moisture content in soil is less, only severe rainfall events can trigger landslides in the study area; while less severe rainfall events can also trigger landslides when the soil is wet. The role of soil wetness in the initiation is used to improve the performance of the conventional methods, and a ROC approach was used for the statistical comparison of different models. Further, the results indicated that the probabilistic threshold using rainfall severity and soil wetness outperformed the conventional approaches with AUC of 0.96, being the most sensitive and specific among the models considered. This result opens new promising perspectives for the development of an operational LEWS in the Idukki district based on a combination of rainfall and soil moisture data. Moreover, this work contributes to strengthen the advancing trend of hydro-meteorological thresholds based on soil moisture, which is gaining a growing attention in landslide studies and that, to date, was lacking evidences in monsoon regions.

Keywords: landslides; rainfall thresholds; LEWS; soil moisture; Idukki 


\section{Introduction}

58

Forecasting landslides and evacuating people from hazardous zones is an important risk reduction strategy (Althuwaynee and Pradhan, 2017). Considering the climate change and associated extreme rainfall phenomenon, the number of rainfall-induced landslides are expected to rise (Alvioli et al., 2018; Chen et al., 2019; Gariano and Guzzetti, 2016). Being a geomorphological process in the landscape evolution (Iida, 1999), the detailed understanding of slope failure mechanisms involves hydrological studies and forecasting of possible failure planes (Agostini et al., 2014) using relevant geotechnical and meteorological parameters. However, these parameters are highly site specific and often difficult to determine with the desired accuracy (Tofani et al., 2017), except that for single slopes or very small basins (Chae et al., 2017), and sophisticated experimental research is required for understanding the mechanism in detail (Kim et al., 2018). Hence, a more practiced approach is needed to forecast the critical conditions which result in the occurrence of landslides using the primary triggering factor i.e. rainfall - with the aid of rainfall thresholds (Caine, 1980; Keefer et al., 1987; Piciullo et al., 2018). Rainfall thresholds can be empirical, probabilistic, or algorithm based (Althuwaynee et al., 2015; Piciullo et al., 2018; Segoni et al., 2018a). All the approaches exploit historical data to find a mathematical relationship between rainfall and the occurrence of landslides in a region, to identify critical rainfall conditions which can trigger landslides in the future. A rainfall event is most commonly characterised in terms of cumulated rainfall event (E), duration (D), and intensity (I) (which are referred to as "rainfall parameters"). Consequently, the thresholds are often defined as cumulated event rainfall vs. duration (ED thresholds) (Lainas et al., 2016; Melillo et al., 2018, 2016; Peruccacci et al., 2017; Teja et al., 2019) or as rainfall intensity vs. duration (ID thresholds) (Battistini et al., 2017; Brunetti et al., 2010; Guzzetti et al., 2008; Lainas et al., 2016; Wu et al., 2019).

When the definition of thresholds is associated with the generation of many false alarms, their usage in operational Landslide Early Warning System (LEWS) may be inappropriate (Aleotti, 2004; Guzzetti et al., 2008; Kirschbaum et al., 2012; Segoni et al., 2018b). Low performances of rainfall 
thresholds are traditionally related to the uncertainties associated with the definition of rainfall parameters, the quality and resolution of the historical data and the intrinsic limitations of the statistical models (Gariano et al., 2020; Marra et al., 2017; Nikolopoulos et al., 2014).

Some authors argued that sometimes the statistical correlation between rainfall parameters and landslide initiation is too weak and that hydro-meteorological thresholds accounting for both rainfall and hydrological (e.g. soil moisture) parameters could provide a stronger and more accurate assessment (Bogaard and Greco, 2018; Jakob et al., 2006; Terlien, 1998). Integrating soil moisture with rainfall thresholds has been proven effective in improving the rainfall thresholds (Abraham et al., 2020b; Segoni et al., 2018c; Zhao et al., 2019a), as the antecedent moisture content plays a key role in the shear strength parameters of soil. The soil moisture conditions play a key role in the infiltration process (Song and Wang, 2019) which significantly influences the initiation of landslides (Alimohammadlou et al., 2014; Baum et al., 2008; Bicocchi et al., 2019; Iverson, 2000; Wei et al., 2020; Yang et al., 2019). Weighted indexes (Glade et al., 2000; Ponziani et al., 2012); and satellite data (Zhao et al., 2019b) can be used for estimating soil moisture values when real-time field monitoring (Abraham et al., 2020c; Dikshit et al., 2018; Uchimura et al., 2015, 2010) cannot be conducted. Hydrological models (Abraham et al., 2020b; Zhao et al., 2019a) can also be used for the estimation of soil moisture content. In the published literature, soil moisture combined with rainfall thresholds has been tested mainly in Mediterranean, temperate and alpine climatic settings, whereas in monsoon regions similar types of tests are almost completely missing (Jakob et al., 2006; Mirus et al., 2018a; Valenzuela et al., 2018; Wicki et al., 2020).

The present work attempts to define statistical rainfall thresholds in Idukki district (India) and to improve their effectiveness by coupling rainfall parameters with soil moisture data. First, ED thresholds are defined using an automatic algorithm-based approach (Melillo et al., 2014). The conditions which may result in landslides and identifies the maximum probable rainfall condition 
the ED thresholds with multiple exceedance probabilities using frequentist method. Then, by using a

111 probabilistic approach (Berti et al., 2012), the effect of event rainfall, duration and intensity on the

112 occurrence of landslides is evaluated (probabilistic rainfall thresholds). Both empirical (Melillo et al., 113 2018, 2016; Peruccacci et al., 2017) and probabilistic approaches (Berti et al., 2012; Dikshit and 114 Satyam, 2019) were considered to establish the relationship between primary triggering factor (rainfall) and the result (landslide), and these are simple statistical approaches that are easy to derive by integrating with a rainfall forecasting system. Similar studies have been conducted for Indian Himalayas (Abraham et al., 2020a; Dikshit and Satyam, 2018, 2019; Teja et al., 2019) and the Western Ghats (Abraham et al., 2020e, 2019); however, these methods were not always found to be operational due to a higher number of false alarms or missed alarms, limiting their applications in LEWS. This study aims to overcome these limitations by integrating soil moisture data along with the rainfall thresholds. The objective is to find if the addition of soil moisture data can perform better than the conventional methods based on the rainfall data alone.

\section{Description of the study area}

The Western Ghats of Indian Peninsula is highly susceptible to rainfall-induced landslides. There is a surge in the number of landslides during monsoon season since 2018 , due to very-high intensity rainfalls. The landslides and floods happened in 2018 severely affected the south Indian states of Kerala and Karnataka. Among the 14 districts in the state of Kerala, 13 are part of the Western Ghats and are susceptible to landslides. Nearly 5.3 million people in the state were affected by the disaster in 2018 (United Nations Development Programme, 2018). The Western Ghats scarps, running the whole extent of the mountain range, are highly prone to landslides. Very-high intensity rainfall, along with the anthropogenic activities, has accelerated the geological processes leading to landslides, making the situation alarming (Kuriakose et al., 2009b).

Idukki is a hilly district in the Western Ghats and is the second largest district in the state of Kerala, in terms of area. This district covers an area of $4358 \mathrm{~km}^{2}$ and derived its name from the word 'Idukku' in the vernacular dialect meaning narrow gorge. This itself indicates the geography of the area. The district is the major power source of Kerala and houses many hydroelectric projects, including the 
famous arch dam of Idukki. About 50\% of the district is covered by forests and Idukki is drained by three major rivers, two flowing westward and one eastward. The rainfall across the district is varying with the least values recorded in the northern side with a long-term average of $1000 \mathrm{~mm}$ while the southern parts record an average rainfall of $5000 \mathrm{~mm}$ (Sajeev and Praveen 2014; Department of Mining and Geology 2016). The southwest monsoon season from June to September contributes 60\% of the annual rainfall and around $24 \%$ is contributed by the North-East monsoon from October to December. Due to varying topography, the climatic conditions in the hill ranges, plateaus and midlands of the district are different from each other.

Fig. 1. Location details of study area. (a) India, and (b) Digital Elevation Model of Idukki (modified using CartoDEM (CartoDEM, 2015)) along with location of rain gauges.

Geologically, Idukki can be divided into three different parts from south to north. The charnockite rocks in the south, migmatitic complex in central portion, and peninsular gneissic complex in the northern part. Granite gneiss is the oldest and predominant group among the peninsular gneissic complex while the charnockite group consists of magnetite quartzite, pyroxene granulite and charnockite (Department of Mining and Geology 2016). Structural cum denudational hills are the predominant geomorphological feature of Idukki. The hills are generally having a thin soil cover overlaid on Precambrian basement rocks. The midlands have a rugged topography with small hills and deep valleys with an average elevation of $50 \mathrm{~m}$. The zone where midlands grades to plateaus are called the foothills, ranging up to $8 \mathrm{~km}$ in width. A major portion of the district belongs to the plateau region, with a large landmass of moderate slope. The elevation of the plateau region goes up to 1500 $\mathrm{m}$, and the regions at an elevation greater than $1500 \mathrm{~m}$ belong to hilly ranges. More than $50 \%$ of the study area is covered by forest loam soils, produced by the weathering of rock under thick forest cover. The midlands are covered by lateritic soil with high permeability and less organic content. The valley portion of the terrain are covered with fine particles of sandy loam to clay type, formed by sedimentation and transportation of hill slopes. The narrow riverbanks consist of fertile alluvial soil and are more common in the midlands. 
Because of its topographic variability and heavy rainfall, the district is highly susceptible to rainfall induced landslides. The typology of landslides in the Western Ghats includes earth and debris slides, rock falls, creep, slump and debris flows_(Abraham et al., 2020d). Due to the thin regolith layer, shallow landslide (Varnes, 1978) is the most common type during prolonged rainfalls (Kuriakose et al., 2009a). Idukki district in particular is mostly affected by the cut slope failures along the major road corridors, disrupting the transportation network in the district. Recent changes in the land use patterns for infrastructure development and agriculture have affected the stability of slopes of this ecologically sensitive zone (Gadgil et al., 2011) and has aggravated the number of landslide disasters (Kuriakose et al., 2009b). Hence the development of an effective regional scale LEWS is highly needed to forecast the future landslides in the region.

\section{Data and Methodology}

The study explores the possibility of using soil moisture data in improving the performance of statistical thresholds. The overall methodology flow chart adopted in this study is shown in Fig 2. The methodology involves data collection from multiple sources, the definition of thresholds and their performance evaluation using different skill scores. For the analysis, historical rainfall, landslide, and soil moisture data were collected. For developing empirical and probabilistic rainfall thresholds, only rainfall and landslide data are required, while for developing probabilistic rainfall thresholds based on rainfall severity and soil wetness (RS threshold), the soil moisture data were integrated with empirical ED thresholds using a probabilistic approach. While the empirical threshold considers the effect of rainfall events which resulted in landslides, the probabilistic thresholds consider both triggering and non-triggering rainfall events for the analysis.

Fig. 2. Methodology of study. 
The dataset used for this study spans from 2010 to 2018 and the historical data from this period was used to derive the empirical and probabilistic thresholds for occurrence of landslides in Idukki district. The daily rainfall data was collected from the Indian Meteorological Department (India Meteorological Department 2019) for four rain gauges within the district. The landslide data was collected from various government agencies and media reports (Abraham et al., 2019) and only landslides for which the date of occurrence was available were used for the analysis. For each rain gauge a reference area was defined and multiple landslides triggered in the same day in each area were considered as one landslide event and rainfall data were collected from the reference rain gauge. By these criteria, 225 landslide events were identified in the study area which were first used as the input for empirical thresholds. For probabilistic thresholds, a total of 5028 rainfall events recorded by the four rain gauges during the study period were considered.

The average daily soil moisture data was collected from Giovanni's website by National Aeronautics and Space Administration Goddard Earth Sciences Data and Information Services Center (NASA GES DISC) (de Jeu and Owe, 2014, 2012; Giovanni, 2020). The data was derived using land parameter retrieval model (LPRM), which is a multi-parameter retrieval algorithm focused on hydrological and climate studies. It retrieves the soil moisture from the microwave observations from sensors. The observed brightness temperatures were used to derive the soil moisture data, using LPRM (Owe et al., 2008). LPRM is based on a forward radiative transfer model and the output is the volumetric soil moisture content in percentage. The soil moisture on the day before the occurrence of landslide, termed as the 'antecedent soil moisture' was used for the analysis in this research. The spatial resolution of the data is $0.25^{\circ} \times 0.25^{\circ}$. The study area (Idukki district) consists of 14 grids of size $0.25^{\circ} \times 0.25^{\circ}$ (Figure 1). After calculating the area of Idukki within each grid, the weighted average was calculated for the whole area, for simplified calculation. This value is called the 'averaged moisture content'. Another term, 'soil wetness' is introduced, to represent a range of antecedent soil moisture, on a scale of 0 to 1 . The soil wetness values were divided into five equal parts, representing different ranges of moisture content. This classification is used to overcome the 
214 limitations associated with using averaged data for a larger area. The value of soil wetness is directly

215 proportional to the moisture content values and indicates the wetness of soil before the landslide.

216 Thus, by using historical rainfall, landslide and soil moisture data, thresholds were defined using

217 multiple approaches for the study area to find the effect of soil moisture on the forecasting 218 performance of the thresholds.

\subsection{Empirical thresholds}

The selection of rain gauges and rainfall parameters plays a critical role in the definition of rainfall thresholds (Abraham et al., 2020e). For the study area, rainfall data from the four available rain gauges were considered for the analysis. The intensity-duration thresholds for the study area was earlier derived from using a nearest rain gauge approach (Abraham et al., 2019), considering 225 landslide events occurred from 2010 to 2018. From the pioneering work of Caine (Caine, 1980), ID thresholds were defined for regions across the globe (Abraham et al., 2020c, 2019; Brunetti et al., 2010; Dikshit and Satyam, 2018; Guzzetti et al., 2008, 2007; Segoni et al., 2018a). Even though intensity can easily be converted to event rainfall and vice-versa, recent literature shows a shift towards defining ED thresholds instead of ID thresholds (Melillo et al., 2018, 2014; Peruccacci et al., 2012; Teja et al., 2019; Zhao et al., 2019a). The reason is that E and D are two mutually independent parameters while $\mathrm{I}$ is a function of $\mathrm{D}$ and $\mathrm{E}$. Hence, for a definition of rainfall thresholds and rainfall event- duration thresholds was carried out by using Calculation of Thresholds for Rainfall Induced Landslides - Tool (CTRL-T) (Melillo et al., 2018, 2014). CTRL-T uses an algorithm-based approach, extracting the rainfall events automatically from the daily precipitation data input. From the extracted events, rainfall conditions that have triggered landslides were identified; and -used to derive the rainfall thresholds for the region. The tool considers a buffer zone around each landslide location, to search for the rain gauge and identify the triggering event. In this study, a search radius of $20 \mathrm{~km}$ is considered, due to the low rain gauge density in the study area. The algorithm also considers a delay 
240 time between the end of rainfall and occurrence of landslide. In this study, the delay time is taken as 24148 hours (Melillo et al., 2014). If no rainfall condition is recreated within this delay time before the 242 occurrence of landslide, the event will be discarded by the algorithm. The algorithm first determines the total event rainfall and duration of rainfall for all identified rainfall events and then to minimise the effect of spatial variability of rainfall distribution, single or multiple rainfall conditions (MRC) likely to result in failures and a weight is assigned to each of them. Then for each landslide, the highest weight was used to identify the reference rain gauge and to choose the maximum probable rainfall conditions (MPRC). In this study, five different threshold lines were defined using CTRL-T, at different exceedance probabilities of $1 \%, 5 \%, 10 \%, 20 \%$ and $50 \%$ (termed as $\mathrm{T}_{1}, \mathrm{~T}_{5}, \mathrm{~T}_{10}, \mathrm{~T}_{20}$ and $\mathrm{T}_{50}$, respectively). Thresholds and related uncertainties were estimated from MPRCs. The defined thresholds are in the form of a power law, determined using the frequentist approach (Brunetti et al., 2010) and can be expressed as:

$$
E=(\alpha \pm \Delta \alpha) D^{(\gamma \pm \Delta \gamma)}
$$

where, $\alpha$ is the scaling parameter or the intercept and $\gamma$ is the shape parameter which denotes the slope of the equation. $\Delta \alpha$ and $\Delta \gamma$ represents the uncertainties associated with $\alpha$ and $\gamma$, respectively. The uncertainties are determined using a bootstrap approach.

\subsection{Probabilistic approach}

The empirical thresholds compare an input value with the defined thresholds and will have a single output (triggering or non-triggering). It is often difficult to decide the exceedance probability to be selected as a threshold beyond which a radical change can be expected in the system (Berti et al., 2012). The discretion between triggering and non- triggering rainfall conditions is not trivial in such cases. To derive the equation, only the triggering rainfall conditions are considered. This increases the chances of false alarms, as numerous rainfall events that cross the threshold line not necessarily trigger landslides. 
265 By considering both triggering and non- triggering rainfalls for analysis, probability-based models are

266 more informative and provide a better option to find extreme events. In this study, a Bayesian

267 approach is used to define probabilistic thresholds (Berti et al., 2012).

\subsubsection{One-dimensional analysis}

269 Bayes theorem applies a conditional probability of some event $L$ (landslide) given the occurrence of 270 another event $X$ (rainfall, expressed in terms of $\mathrm{E}$, I or D). This is also called the posterior probability, $271 P(X \mid L)$. It can be calculated as follows (Berti et al., 2012):

$$
P(L \mid X)=\frac{P(X \mid L) * P(L)}{P(X)}
$$

272 where, $P(X \mid L)$ is the conditional probability of occurrence of rainfall of magnitude $X$, when a 273 landslide occurs. This is also called as a likelihood.

$274 P(L)$ is the prior probability of occurrence of landslide regardless of the occurrence rainfall 275 magnitude.

$276 P(X)$ is the marginal probability of $X$, which can be defined as the probability of occurrence of 277 rainfall regardless of the occurrence of landslides. The terms can be calculated mathematically using 278 relative frequencies. Let $N_{R}$ be the total number of rainfall events during study period, $N_{L}$ be the total 279 number of landslides occurred, $N_{X}$ be the number of rainfall events with magnitude $X$ and $N_{(X \mid L)}$ be 280 the number of rainfall events with magnitude $X$ that resulted in landslides. The probabilities can be 281 computed as (Berti et al., 2012):

$$
\begin{aligned}
& P(L) \approx \frac{N_{L}}{N_{R}} \\
& P(X) \approx \frac{N_{X}}{N_{R}}
\end{aligned}
$$




$$
P(X \mid L) \approx \frac{N_{(X \mid L)}}{N_{L}}
$$

283 Considering the rainfalls that resulted in landslides only will give us partial information, the

284 likelihood. To understand the influence of rainfall of magnitude $X$, it is important to compare the prior 285 probability with the posterior probability.

\subsubsection{Two-dimensional analysis}

287 Two-dimensional case is the extension of Eq. 2 by considering two conditions $X, Y$ instead of the 288 single condition $X$ in Eq. 2. In the initial analysis, we consider $X$ and $Y$ as magnitude of two rainfall 289 parameters (E,D ; I,D; E,I). The calculation of prior, marginal and conditional probabilities are given 290 below:

$$
\begin{gathered}
P(L \mid X, Y)=\frac{P(X, Y \mid L) * P(L)}{P(X, Y)} \\
P(L) \approx \frac{N_{L}}{N_{R}} \\
P(X, Y) \approx \frac{N_{X, Y}}{N_{R}} \\
P(X, Y \mid L) \approx \frac{N_{(X, Y \mid L)}}{N_{L}}
\end{gathered}
$$

292 The study explores the effect of antecedent soil moisture content using a two-dimensional probabilistic analysis. During the second phase, we considered rainfall severity in ED plane and soil wetness as $X$ and $Y$, respectively. Based on the values of soil wetness, five different categories were considered for analysis viz, less than $0.2,0.2$ to $0.4,0.4$ to $0.6,0.6$ to 0.8 , and 0.8 to 1 . The categories 
based on rainfall severity were less than $T_{1}, T_{1}$ to $T_{5}, T_{5}$ to $T_{10}, T_{10}$ to $T_{20}, T_{20}$ to $T_{50}$ and greater than $\mathrm{T}_{50}$. Thus, the two-dimensional plane was divided into 30 cells as a 6 x 5 matrix as shown in Fig. 6 . These values were used for the definition of RS threshold.

\section{Results}

\subsection{Empirical thresholds}

CTRL-T tool considered 177 landslide events out of the 225 and the rest were discarded to avoid introduction of relevant spatio-temporal uncertainties in the analysis. The uncertainties are associated with the less rain gauge density in the study area. As described earlier, the landslides for which responsible rainfall conditions were not identified were discarded. This can be due to a distance more than $20 \mathrm{~km}$ between the location of rain gauges and landslide or due to a delay time more than 48 hours after the end of any rainfall event. The algorithm forecasted rainfall thresholds with various exceedance probability both in normal and logarithmic plot (Fig. 3). The threshold lines of 1\%, 5\%, $10 \%, 20 \%$ and $50 \%$ exceedance probabilities were used to classify the events into six categories based on the severity of rainfall. These lines are named $T_{1}, T_{5}, T_{10}, T_{20}$ and $T_{50}$, respectively. The slope of threshold lines in logarithmic plot was found to be $0.57 \pm 0.03$. This value is not in good agreement with the ID thresholds defined for the area in a previous study (Abraham et al., 2019). Though both the studies used frequentist approach for the definition of thresholds, the process of identification of responsible rainfall event was different. In the previous study (Abraham et al., 2019), the responsible rainfalls were identified using a Thiessen polygon approach manually, while in this study, the automatic algorithm, CTLRL-T is used for identifying the responsible rainfall event. The parameters of threshold lines and the uncertainties associated are listed in Table 1.

Fig. 3. Rainfall event - duration thresholds for Idukki district

Table 1. Values of $\alpha, \gamma$ and the uncertainties associated with different exceedance probabilities 
322 The range of duration of rainfalls considered for analysis vary from 1 to 26 days. For the thresholds to 323 be reliable, the relative uncertainty $(\Delta x / x$ for any variable $x)$ should be less than $10 \%$. Here the relative uncertainty of $\gamma$ is $5.2 \%$. But with higher exceedance probabilities, the relative uncertainty of $\alpha$ is crossing this limiting value.

With 5\% exceedance probability, $20.19 \mathrm{~mm}$ rainfall can trigger a landslide in the region for a duration of 24 hours and when the duration is 624 hours, a rainfall of $129 \mathrm{~mm}$ can trigger landslides in the region. For a better understanding of the effect of each rainfall parameter on the occurrence of landslides, probabilistic rainfall thresholds were defined for the area.

\subsection{Probabilistic thresholds}

The maximum probable rainfall conditions which were used for the definition of ED thresholds were considered as the triggering rainfall events for the probabilistic analysis. Thus, out of the 5028 rainfall events considered, 177 events were identified as triggering events by CTRL- T algorithm and the rest 4851 events were considered as non-triggering rainfall events. In the one-dimensional case, six categories of rainfall duration, five categories of cumulated rainfall event and seven categories of rainfall intensity were considered. The results are plotted in Fig. 4 (a-f); where Fig. 4a, c and e depict the prior probability, marginal probability and likelihood, and Fig. $4 \mathrm{~b}, \mathrm{~d}$ and $\mathrm{f}$ depict the prior and posterior probabilities. The variable $X$ in Eq. (2-5) is replaced with $\mathrm{D}, \mathrm{E}$ and $\mathrm{I}$ in the respective graphs. $P(L)$ being a constant parameter (value 0.035 in this study), the ratio of $P(X \mid L)$ to $P(X)$ determines the variation of posterior probability values. Hence when $P(X \mid L)>P(L)$, the posterior probability is greater than prior probability and vice versa. The more the variation between prior and posterior probability, the more significant the variable is. It can be seen, that for duration and event rainfall, for the largest values of variables, the values of $P(L \mid X)$ is less than $P(L)$, while in the case of intensity, high intensity rainfalls are more probable to trigger landslides in the region. The plots of $P(X)$ and $P(X \mid L))$ are well above the plot of prior probability in all the cases. Intensity was found to be the most significant variable, with the maximum ratio between posterior and prior probabilities. 
The maximum posterior probability when the control parameter is D was found to be 0.053 where the value is 0.103 and 0.116 in the case of $\mathrm{E}$ and $\mathrm{I}$, respectively. Maximum probability occurs when the duration is between $120 \mathrm{~h}$ to $240 \mathrm{~h}$; event rainfall is between $100 \mathrm{~mm}$ to $200 \mathrm{~mm}$; and intensity is greater than $3 \mathrm{~mm} / \mathrm{h}$.

Fig. 4. Prior, conditional, marginal and posterior probabilities with respect to rainfall parameters. (a,

b) Duration; (c, d) Event rainfall; and (e, f) Intensity.

To evaluate the joint occurrence of two parameters, two-dimensional Bayesian analysis were conducted with data on three different planes (Fig. 5). The two-dimensional space for each analysis was divided into small cells based on the categories of parameters used for one-dimensional analysis. Hence the ID plane is a $7 \times 6$ matrix, ED plane is a $5 \times 6$ matrix and the EI plane is a $5 \times 7$ matrix. There are several no data points in all three cases, due to the lower number of landslides considered for the analysis. As identified from the one-dimensional analysis, E and I were found to be more critical parameters than D. This is the reason why this study has considered all three different combinations of the control parameters even though the empirical thresholds are defined on ED plane only. The maximum probability value was obtained on EI plane, when the intensity value is less than $0.5 \mathrm{~mm} / \mathrm{h}$ and event rainfall is between $100 \mathrm{~mm}$ to $200 \mathrm{~mm}$, with a value of 0.54 .

Fig. 5. Two-dimensional posterior probabilities of occurrence of landslide on (a) ID plane, (b) ED

$$
\text { plane, and (c) EI plane. }
$$

It is evident from Fig. 6 that even less severe rainfall events when falling on a moist soil can trigger landslides in the region. Most of the landslides for which rainfall events were less severe happened on days with higher soil wetness. Also, when the rainfall event is severe, even dry soil can be susceptible to landslides. The maximum probability of 0.49 was observed when the rainfall severity was between $\mathrm{T}_{20}$ to $\mathrm{T}_{50}$ and the soil wetness was between 0.8 to 1 . With the available data, when the antecedent soil moisture is less, only extremely severe rainfall conditions can trigger landslides in the area. This 
affects the performance of the ED thresholds considerably. For different antecedent soil moisture conditions, this makes it easier to decide the threshold line to be used.

Fig. 6. Two-dimensional Bayesian probabilities for occurrence of landslides based on rainfall severity and soil wetness.

\section{Discussions}

To verify the performance of all models and to understand which model is performing better for the study area, different thresholds should be compared quantitatively (Lagomarsino et al., 2015). In this study, empirical thresholds on ED plane, probabilistic thresholds on all three combinations of control parameters (ED, ID and EI) and also a two-dimensional Bayesian approach by combining empirical ED thresholds with soil moisture have been derived. The maximum probability value obtained in the two-dimensional analysis was in the case of EI thresholds, and the value is 0.54 . The value was obtained when the intensity is less than $0.5 \mathrm{~mm} / \mathrm{h}$ and event rainfall is between 100 to $200 \mathrm{~mm}$. This implies a prolonged duration of 8 days or more. The intensity value is too low in this case, yet the probability value is the maximum. The definition of 2-dimensional Bayesian probability majorly depends upon the relative occurrence of landslides when the rainfall conditions are satisfied and the occurrence of rainfall events with specified conditions. The number of events with the specified EI conditions were less, but more than half of them have resulted in landslides based on the historical data. Thus, the probability of occurrence of landslides is higher in this case. This result points towards the significance of using a physical parameter such as soil moisture for the definition of threshold. The top regolith layer throughout the district consists of forest loam, lateritic soil, alluvial soils etc, with higher fine fraction (Department of Mining and Geology Kerala, 2016). The less permeable soil has a higher water holding capacity and the moisture content increases when the rainfall is continuous. The prolonged rainfall has thus reduced the shear strength of soil and the landslide has happened at a very less intensity value. This complicated process is simplified by using a statistical 
approach, by considering the effect of soil wetness. To understand the performance of such a model with respect to the meteorological thresholds, a quantitative comparison is required.

400 An ROC curve approach was used for quantitative comparison. ROC curve is a tool to understand the 401 performance of a model with a binary outcome. Each threshold value can forecast two outcomes for a day; 'landslides' or 'no landslides. If the threshold condition is crossed, the model forecasts 'landslides' and otherwise, 'no landslides. When the forecasting is correct and landslide occurs, it is termed as a true positive (TP). Another possibility of correct outcome is the result 'no landslides' on a day in which landslides do not occur. This can be counted as a true negative $(T N)$ result. When the forecasting goes wrong, it also has two possible outcomes. 'Landslides' forecasted on a non-landslide day, which is a false positive $(F P)$ or simply a false alarm and 'no landslides' forecasted on a day in which landslides occur, termed as false negatives $(F N)$ or missed alarms. A perfect model should only have true outcomes, without any false alarms or missed alarms.

410 A ROC curve is a plot with a false positive rate of a model on $\mathrm{x}$-axis and a true positive rate on y axis.

411 It evaluates the overall performance of the model. The true positive rate is also called the sensitivity 412 of the model. It provides the proportion of landslide occurrences which are correctly identified $413(T P /(T P+F N))$. The specificity of a model is the true negative rate and is the ratio of $T N$ to the 414 sum of $T N$ and $F P$. The false positive rate can be calculated by subtracting specificity value from 1. 415 An ideal model is expected to have both sensitivity and specificity values as 1 . Hence the point $(0,1)$ on ROC curve is called the perfect point. Points which are closer to this perfect point has a better 417 performance. Also, the model with better performance is the one with a maximum area under the curve (AUC) among the different models considered. Threat score and True Skill Statistic (TSS) are two other parameters which were used to understand the performance of a model (Mirus et al., 2018b). Threat score is defined as the ratio of $T P$ to the sum of $T P, F P$ and $F N$. TSS is the difference between sensitivity and false positive rate. For an ideal model, the value of both these variables should be 1 .

ROC curves for all models considered in the study are plotted in Fig. 7 and the statistical attributes are listed in Table 2. From Fig. 7, it can be observed that the RS threshold covers the maximum area in 
the plane with an AUC of 0.96. The empirical ED threshold has the second highest AUC of 0.86. All the three probabilistic rainfall thresholds have very close AUC values as observed in Fig. 7. EI threshold covers a larger area than the other two, indicating its better performance in comparison with the other two probabilistic rainfall thresholds. The distance from perfect point is minimum in the case of RS thresholds, in the case of critical probabilities 0.1 and 0.15 . It can also be observed that the value of threat score and TSS are maximum in the case of RS thresholds. The maximum value of threat score is obtained as 0.24 and TSS as 0.90 , both in the case of RS thresholds with critical probability 0.1 , which is also the closest one to the perfect point.

Fig. 7. ROC curves for the derived thresholds. Sensitivity is the ability of a model to correctly identify the landslide events and Specificity is the ability to correctly identify the non-landslide events

Looking into the details in Table 2, it confirms with the literature as the empirical thresholds result in many false alarms, making it inadequate to use in an LEWS. The number of false alarms can considerably be reduced by using probabilistic rainfall thresholds, as listed in Table 2 . The number of $F P$ in the case of probabilistic ED. ID and EI are much lesser than the other two models considered. But this reduction in false alarms comes with the cost of a higher number of missed alarms $(F N)$. While 171 landslide events out of the 177 events are correctly forecasted by the empirical ED threshold line $\mathrm{T}_{1}$, and 172 are correctly forecasted by RS threshold when the critical probability is 0.05 , the maximum number of correct outcomes for the other probabilistic models are 106, 105 and 117 on ED, ID and EI planes respectively. For improving the performance, we need to balance the number of false alarms and missed alarms, which is achieved by using RS threshold. The RS threshold has $F N$ numbers comparable with that of probabilistic rainfall thresholds, minimising the false alarms and by incorporating an additional filter using soil wetness, it reduces the number of false alarms when compared to the empirical ED threshold.

Table 2. Statistical attributes for quantitative comparison.

The probabilistic rainfall thresholds have high specificity values, pointing to their ability to correctly forecast the days without landslides, but with very less values of sensitivity. The points on ROC curves for probabilistic rainfall thresholds are therefore closer to both the axes, reducing the AUC. 
452 Even though the points have high specificity values, they are located far from the perfect point, due to 453 their inefficiency in correctly forecasting the occurrence of landslides. The RS threshold with a 454 critical probability of 0.1 is the closest one to the perfect point, correctly forecasting 167 landslide occurrences.

From the analysis, the rainfall and soil wetness conditions for which the probability of occurrence is more than 0.1 should be considered critical. This makes it easier to identify the empirical ED threshold line for different values of soil wetness. The critical conditions are mentioned in Table 3.

From Table 3, it can be understood that when soil wetness is less than $0.2, \mathrm{~T}_{50}$ line of empirical ED thresholds should be considered as critical, when the soil wetness is between 0.2 to $0.4, T_{5}$ can be

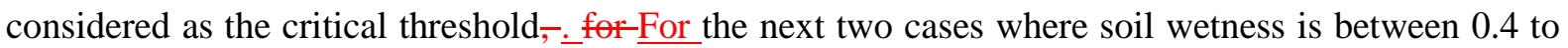
$0.8, \mathrm{~T}_{10}$ threshold line can be considered as critical if the critical probability is 0.1 . In this case, the threshold line for 0.2 to 0.4 is $\mathrm{T}_{5}$, which is below the threshold line for soil wetness from 0.4 to 0.8 . This variation can be due to the smaller number of data points considered in this study. With the available data points, very less cases are reported when the soil wetness is between 0.4 to 0.8 , and the rainfall severity is below $\mathrm{T}_{10}$. To avoid any possible missed alarms due to the limitations of the dataset considered, the threshold for soil wetness between 0.4 to 0.8 is considered as $\mathrm{T}_{1}$, for which the probability of occurrence of landslides is 0.05 in this study. This variation in the critical probability ensures the physical validity and easy export of the model. and when the soil wetness is between 0.8 to 1 , even rainfall which are - is below $\mathrm{T}_{1}$ can trigger landslides. Hence, for the last condition, we defined the critical case as $\mathrm{T}_{\min }$ where $\mathrm{T}_{\min }$ represents the threshold line with minimum exceedance probability, close to zero. Practically, it represents any possible rainfall condition. The 
below $\mathrm{T}_{10}$ If the thre has a in of

is $T_{10}=$

The soil wetness data can be collected from daily satellite observations as taken in this study, or from real-time field observation using sensors. The severity of rainfall for each day can be estimated from the rainfall forecasts. Using these two inputs, the possibility of occurrence of landslide can be estimated using the conditions mentioned in Table 3. With higher exceedance probabilities, the relative uncertainty of $\alpha$ of ED threshold is crossing this limiting value. Similar results are observed when the rainfall data used is of daily temporal resolution (Teja et al., 2019).

The type of landslides is also an important factor in identifying the associated rainfall. For example, rockfalls may be triggered without any rainfall, debris flows are often triggered by short duration (maybe less than 1 hour) and high intensity (Kean et al., 2011), and shallow landslides are triggered by short-term rainstorms of high-intensity or long-duration rainfall of low to medium intensity (Guzzetti et al., 2008). This is the main reason why the models (ED, and RS) often associated with the disadvantage of higher false alarms. Even though the false alarms are considerably reduced in RS thresholds, it needs further enhancements to be used in an LEWS. There are chances that the model may miss alarms for rock-falls, which can be triggered with no rainfall. In the case of flow like landslides such as debris flows, the failure can be triggered by very short, high intensity rainfalls. Such rainfall events may trigger landslides in relatively dry soils as well. In this case, even if the antecedent soil wetness is less than 0.2 , if the rainfall severity is greater than $\mathrm{T}_{\underline{\underline{0}}}$, the model will issue a warning. If an event of severity less than $\mathrm{T}_{50}$ triggers such an event, the model may miss the alarm. With a higher number of data points and better resolution of rainfall data, this can be improved, and better results can be expected.

\section{Conclusions}

This study has been conducted to evaluate the effect of antecedent soil moisture content to improving the performance of empirical and probabilistic thresholds for Idukki district in India. The district is 
suffering from landslides ranging from cut slope failures to debris flows during monsoon seasons. The recent disasters that happened in 2018 and 2019 in the district emphasises the requirement of a landslide early warning system for the region.

In this study, empirical rainfall thresholds on ED plane was derived for the study area using an algorithm-based approach. It was found that with 5\% exceedance probability, $20.19 \mathrm{~mm}$ rainfall can trigger a landslide in the region for a duration of 24 hours, and when the duration is 624 hours, a rainfall of $129 \mathrm{~mm}$ can trigger landslides in the region.

511 To evaluate the influence of each rainfall parameter on the occurrence of landslides, Bayesian analyses were conducted for both one-dimensional and two-dimensional cases. It was found that both intensity and event rainfall have influence on the occurrence of landslides, and most of the events happened when the rainfall happened in lesser duration. From two-dimensional analysis, the probabilities on EI plane were found to have the maximum values.

To evaluate the effect of soil wetness, another two-dimensional Bayesian approach was conducted, and it was observed that when the soil is relatively dry, severe rainfall events are required to trigger landslides and when the soil is wet, also milder rainfall conditions can trigger landslides in the study area.

A statistical comparison between the considered models was used to find out the best performing model. The comparison was carried out by using a ROC curve approach, where the RS threshold was found to have the maximum AUC of 0.96, among the models considered in this study. The empirical ED threshold generated a relevant number of false alarms, resulting in a low specificity value, while the disadvantage associated with the probabilistic thresholds was the low sensitivity due to a large number of missed alarms. The proposed method, which combines empirical thresholds with soil wetness using a probabilistic approach, performs better than both the root models by optimising the number of false alarms and missed alarms. Based on the comparison, it was found that an RS threshold of probability 0.1 should be considered critical for the study area and critical rainfall severity conditions were identified for each soil wetness condition. The performance could be further 
enhanced in the future by using hourly rainfall data with more dense rain gauge network for the area. Moreover, real-time monitoring of moisture content data for different locations in the study area can also contribute to better resolution soil moisture data and thereby improving the performance of the model.

The results of the study therefore open new promising perspectives for the development of an operational LEWS in the Idukki district, by combining rainfall and soil moisture data. At the same time, this work provides evidences from a monsoon region about the advances brought by hydrometeorological thresholds based on soil moisture, which is gaining a growing attention in landslide studies all over the world but before today it was relatively unexplored for the setting of LEWS in the study area. Unfortunately, the use of soil moisture data in operational LEWS with short lead times is technically difficult, consequently another option to be explored is the use of antecedent rainfall conditions as a proxy to the soil moisture, which can be a simpler method to express the soil wetness conditions (Leonarduzzi and Molnar, 2020; Segoni et al., 2018b). More studies must be conducted for this region, to develop an effective LEWS which could obtain a fair compromise between the simplicity of the approach and the quality of the forecasting performance.

\section{Acknowledgements}

Analyses and visualizations used in this study were produced with the Giovanni online data system, developed and maintained by the NASA GES DISC. The research was supported by Università degli Studi di Firenze under the Grant 58517_INTERNAZIONALIZZAZIONE

\section{References}

Abraham, M.T., Pothuraju, D., Satyam, N., 2019. Rainfall Thresholds for Prediction of Landslides in Idukki, India: An Empirical Approach. Water 11, 2113. https://doi.org/10.3390/w11102113

Abraham, M.T., Satyam, N., Kushal, S., Rosi, A., Pradhan, B., Segoni, S., 2020a. Rainfall Threshold Estimation and Landslide Forecasting for Kalimpong, India Using SIGMA Model. Water 12, 
556

557

Abraham, M.T., Satyam, N., Pradhan, B., Alamri, A.M., 2020b. Forecasting of landslides using rainfall severity and soil wetness: A probabilistic approach for Darjeeling Himalayas. Water (Switzerland) 12, 1-19. https://doi.org/10.3390/w12030804

Abraham, M.T., Satyam, N., Pradhan, B., Alamri, A.M., 2020c. IoT-Based Geotechnical Monitoring of Unstable Slopes for Landslide Early Warning in the Darjeeling Himalayas. Sensors 20, 2611. https://doi.org/10.3390/s20092611

Abraham, M.T., Satyam, N., Reddy, S.K.P., Pradhan, B., 2020d. Runout modeling and calibration of friction parameters of Kurichermala debris flow, India. Landslides. https://doi.org/10.1007/s10346-020-01540-1

Abraham, M.T., Satyam, N., Rosi, A., Pradhan, B., Segoni, S., 2020e. The Selection of Rain Gauges and Rainfall Parameters in Estimating Intensity-Duration Thresholds for Landslide Occurrence: Case Study from Wayanad (India). Water 12, 1000. https://doi.org/10.3390/w12041000

Agostini, A., Tofani, V., Nolesini, T., Gigli, G., Tanteri, L., Rosi, A., Cardellini, S., Casagli, N., 2014. A new appraisal of the Ancona landslide based on geotechnical investigations and stability modelling. Q. J. Eng. Geol. Hydrogeol. 47, 29-43. https://doi.org/10.1144/qjegh2013-028

Aleotti, P., 2004. A warning system for rainfall-induced shallow failures. Eng. Geol. 73, 247-265. https://doi.org/10.1016/j.enggeo.2004.01.007

Alimohammadlou, Y., Najafi, A., Gokceoglu, C., 2014. Estimation of rainfall-induced landslides using ANN and fuzzy clustering methods: A case study in Saeen Slope, Azerbaijan province, Iran. Catena 120, 149-162. https://doi.org/10.1016/j.catena.2014.04.009

Althuwaynee, O.F., Pradhan, B., 2017. Semi-quantitative landslide risk assessment using GIS-based exposure analysis in Kuala Lumpur City. Geomatics, Nat. Hazards Risk 8, 706-732. https://doi.org/10.1080/19475705.2016.1255670

Althuwaynee, Omar, F., Pradhan, B., Ahmad, N., 2015. Estimation of rainfall threshold and its use in 
landslide hazard mapping of Kuala Lumpur metropolitan and surrounding areas. Landslides 12, 861-875.

582

Alvioli, M., Melillo, M., Guzzetti, F., Rossi, M., Palazzi, E., von Hardenberg, J., Brunetti, M.T., Peruccacci, S., 2018. Implications of climate change on landslide hazard in Central Italy. Sci. Total Environ. 630, 1528-1543. https://doi.org/10.1016/j.scitotenv.2018.02.315

Battistini, A., Rosi, A., Segoni, S., Lagomarsino, D., Catani, F., Casagli, N., 2017. Validation of landslide hazard models using a semantic engine on online news. Appl. Geogr. 82, 59-65. https://doi.org/10.1016/j.apgeog.2017.03.003

Baum, R.L., Savage, W.Z., Godt, J.W., 2008. TRIGRS — A Fortran Program for Transient Rainfall Infiltration and Grid-Based Regional Slope Stability Analysis.

Berti, M., Martina, M.L.V., Franceschini, S., Pignone, S., Simoni, A., Pizziolo, M., 2012. Probabilistic rainfall thresholds for landslide occurrence using a Bayesian approach. J. Geophys. Res. Earth Surf. 117, 1-20. https://doi.org/10.1029/2012JF002367

Bicocchi, G., Tofani, V., D’Ambrosio, M., Tacconi-Stefanelli, C., Vannocci, P., Casagli, N., Lavorini, G., Trevisani, M., Catani, F., 2019. Geotechnical and hydrological characterization of hillslope deposits for regional landslide prediction modeling. Bull. Eng. Geol. Environ. 78, 4875-4891. https://doi.org/10.1007/s10064-018-01449-z

Bogaard, T., Greco, R., 2018. Invited perspectives: Hydrological perspectives on precipitation intensity-duration thresholds for landslide initiation: Proposing hydro-meteorological thresholds. Nat. Hazards Earth Syst. Sci. 18, 31-39. https://doi.org/10.5194/nhess-18-31-2018

Brunetti, M.T., Peruccacci, S., Rossi, M., Luciani, S., Valigi, D., Guzzetti, F., 2010. Rainfall thresholds for the possible occurrence of landslides in Italy. Nat. Hazards Earth Syst. Sci. 10, 447-458. https://doi.org/10.5194/nhess-10-447-2010

Caine, N., 1980. The rainfall intensity-duration control of shallow landslides and debris flows: An update. Geogr. Ann. Ser. A, Phys. Geogr. 62, 1-2, 23-27. 
CartoDEM, 2015. CartoDEM : a national digital elevation model from Cartosat-1 stereo data. Natl. Remote Sens. Centre, Hyderabad, Dep. Space, Gov. India.

Chae, B.G., Park, H.J., Catani, F., Simoni, A., Berti, M., 2017. Landslide prediction, monitoring and early warning: a concise review of state-of-the-art. Geosci. J. 21, 1033-1070. https://doi.org/10.1007/s12303-017-0034-4

Chen, C.-W., Tung, Y.-S., Liou, J.-J., Li, H.-C., Cheng, C.-T., Chen, Y.-M., Oguchi, T., 2019. Assessing landslide characteristics in a changing climate in northern Taiwan. CATENA 175, 263-277. https://doi.org/10.1016/j.catena.2018.12.023

de Jeu, R. (Vrije U.A., Owe, M. (NASA G., 2014. AMSR2/GCOM-W1 surface soil moisture (LPRM) L3 1 day 25 km x 25 km descending V001, Edited by Goddard Earth Sciences Data and Information Services Center (GES DISC) (Bill Teng), Greenbelt, MD, USA, Goddard Earth Sciences Data and Information Services Cente. https://doi.org/10.5067/CGDEOBASZ178

de Jeu, R. (Vrije U.A., Owe, M. (NASA G., 2012. TMI/TRMM surface soil moisture (LPRM) L3 1 day $25 \mathrm{~km}$ x $25 \mathrm{~km}$ nighttime V001, Edited by Goddard Earth Sciences Data and Information Services Center (GES DISC) (Bill Teng), Greenbelt, MD, USA, Goddard Earth Sciences Data and Information Services Center (GES. https://doi.org/10.5067/GWHRZEL8SA21

Department of Mining and Geology Kerala, 2016. District Survey Report of Minor Minerals. Thiruvananthapuram.

Dikshit, A., Satyam, D.N., 2018. Estimation of rainfall thresholds for landslide occurrences in Kalimpong, India. Innov. Infrastruct. Solut. 3. https://doi.org/10.1007/s41062-018-0132-9

Dikshit, A., Satyam, D.N., Towhata, I., 2018. Early warning system using tilt sensors in Chibo, Kalimpong, Darjeeling Himalayas, India. Nat. Hazards 94, 727-741. https://doi.org/10.1007/s11069-018-3417-6

Dikshit, A., Satyam, N., 2019. Probabilistic rainfall thresholds in Chibo, India: estimation and validation using monitoring system. J. Mt. Sci. 16, 870-883. https://doi.org/10.1007/s11629- 
631 Gadgil, M., Krishnan, B.J., Ganeshaiah, K.N., Vijayan., V.S., Borges, R., Sukumar, R., Noronha, L., 632 Nayak, V.S., Subramaniam, D.K., Varma, R.V., Gautam, S.P., Navalgund, R.R., Subrahmanyam, G.V., 2011. Report of the Western Ghats Ecology Expert Panel (WGEEP).

Gariano, S.L., Guzzetti, F., 2016. Landslides in a changing climate. Earth-Science Rev. 162, 227-252. https://doi.org/10.1016/j.earscirev.2016.08.011

Gariano, S.L., Melillo, M., Peruccacci, S., Brunetti, M.T., 2020. How much does the rainfall temporal resolution affect rainfall thresholds for landslide triggering? Nat. Hazards 100, 655-670. https://doi.org/10.1007/s11069-019-03830-x

Giovanni, 2020. NASA GES DISC [WWW Document].

Glade, T., Crozier, M., Smith, P., 2000. Applying probability determination to refine landslidetriggering rainfall thresholds using an empirical “Antecedent Daily Rainfall Model.” Pure Appl. Geophys. 157, 1059-1079. https://doi.org/10.1007/s000240050017

Guzzetti, F., Peruccacci, S., Rossi, M., Stark, C.P., 2008. The rainfall intensity-duration control of shallow landslides and debris flows: An update. Landslides 5, 3-17. https://doi.org/10.1007/s10346-007-0112-1

Guzzetti, F., Peruccacci, S., Rossi, M., Stark, C.P., 2007. Rainfall thresholds for the initiation of

Iida, T., 1999. A stochastic hydro-geomorphological model for shallow landsliding due to rainstorm. Catena 34, 293-313. https://doi.org/10.1016/S0341-8162(98)00093-9 [WWW Document]. 
Jakob, M., Holm, K., Lange, O., Schwab, J.W., 2006. Hydrometeorological thresholds for landslide initiation and forest operation shutdowns on the north coast of British Columbia. Landslides 3, 228-238. https://doi.org/10.1007/s10346-006-0044-1

Kean, J.W., Staley, D.M., Cannon, S.H., 2011. In situ measurements of post - fire debris flows in southern California : Comparisons of the timing and magnitude of 24 debris - flow events with rainfall and soil moisture conditions. J. Geophys. Res. 116, 1-21. https://doi.org/10.1029/2011JF002005

Keefer, D.K., Wilson, R.C., Mark, R.K., Brabb, E.E., Iii, W.M.B., Ellen, S.D., Harp, E.L., Wieczorek, G.F., Alger, C.S., Zatkint, R.S., 1987. Real-Time Landslide Warning During Heavy Rainfall. Science (80-. ). 238, 921-925.

Kim, M.S., Onda, Y., Uchida, T., Kim, J.K., Song, Y.S., 2018. Effect of seepage on shallow landslides in consideration of changes in topography: Case study including an experimental sandy slope with artificial rainfall. Catena 161, 50-62. https://doi.org/10.1016/j.catena.2017.10.004

Kirschbaum, D.B., Adler, R., Hong, Y., Kumar, S., Peters-Lidard, C., Lerner-Lam, A., 2012. Advances in landslide nowcasting: Evaluation of a global and regional modeling approach. Environ. Earth Sci. 66, 1683-1696. https://doi.org/10.1007/s12665-011-0990-3

Kuriakose, S.L., Devkota, S., Rossiter, D.G., Jetten, V.G., 2009a. Prediction of soil depth using environmental variables in an anthropogenic landscape, a case study in the Western Ghats of Kerala, India. Catena 79, 27-38. https://doi.org/10.1016/j.catena.2009.05.005

Kuriakose, S.L., Sankar, G., Muraleedharan, C., 2009b. History of landslide susceptibility and a chorology of landslide-prone areas in the Western Ghats of Kerala, India. Environ. Geol. 57, 1553-1568. https://doi.org/10.1007/s00254-008-1431-9

Lagomarsino, D., Segoni, S., Rosi, A., Rossi, G., Battistini, A., Catani, F., Casagli, N., 2015. 

Quantitative comparison between two different methodologies to define rainfall thresholds for landslide forecasting. Nat. Hazards Earth Syst. Sci. 15, 2413-2423. https://doi.org/10.5194/nhess-15-2413-2015

Lainas, S., Sabatakakis, N., Koukis, G., 2016. Rainfall thresholds for possible landslide initiation in wildfire-affected areas of western Greece. Bull. Eng. Geol. Environ. 75, 883-896. https://doi.org/10.1007/s10064-015-0762-5

Leonarduzzi, E., Molnar, P., 2020. Data limitations and potential of hourly and daily rainfall thresholds for shallow landslides. Nat. Hazards Earth Syst. Sci. Discuss. 1-25. https://doi.org/10.5194/nhess-2020-125

Marra, F., Destro, E., Nikolopoulos, E.I., Zoccatelli, D., Dominique Creutin, J., Guzzetti, F., Borga, M., 2017. Impact of rainfall spatial aggregation on the identification of debris flow occurrence thresholds. Hydrol. Earth Syst. Sci. 21, 4525-4532. https://doi.org/10.5194/hess-21-4525-2017

Melillo, M., Brunetti, M.T., Peruccacci, S., Gariano, S.L., Guzzetti, F., 2016. Rainfall thresholds for the possible landslide occurrence in Sicily (Southern Italy) based on the automatic reconstruction of rainfall events. Landslides 13, 165-172. https://doi.org/10.1007/s10346-0150630-1

Melillo, M., Brunetti, M.T., Peruccacci, S., Gariano, S.L., Guzzetti, F., 2014. An Algorithm for the objective reconstruction of rainfall events responsible for landslides. Landslide Dyn. ISDR-ICL Landslide Interact. Teach. Tools Vol. 1 Fundam. Mapp. Monit. 12, 311-320. https://doi.org/10.1007/978-3-319-57774-6_33

Melillo, M., Brunetti, M.T., Peruccacci, S., Gariano, S.L., Roccati, A., Guzzetti, F., 2018. A tool for the automatic calculation of rainfall thresholds for landslide occurrence. Environ. Model. Softw. 105, 230-243. https://doi.org/10.1016/j.envsoft.2018.03.024

Mirus, B.B., Becker, R.E., Baum, R.L., Smith, J.B., 2018a. Integrating real-time subsurface hydrologic monitoring with empirical rainfall thresholds to improve landslide early warning. 
Mirus, B.B., Morphew, M.D., Smith, J.B., 2018b. Developing hydro-meteorological thresholds for shallow landslide initiation and early warning. Water (Switzerland) 10, 1-19. https://doi.org/10.3390/W10091274

Nikolopoulos, E.I., Crema, S., Marchi, L., Marra, F., Guzzetti, F., Borga, M., 2014. Impact of uncertainty in rainfall estimation on the identification of rainfall thresholds for debris flow occurrence. Geomorphology 221, 286-297. https://doi.org/10.1016/j.geomorph.2014.06.015

Owe, M., de Jeu, R., Holmes, T., 2008. Multisensor historical climatology of satellite-derived global land surface moisture. J. Geophys. Res. Earth Surf. 113, 1-17. https://doi.org/10.1029/2007JF000769

Peruccacci, S., Brunetti, M.T., Gariano, S.L., Melillo, M., Rossi, M., Guzzetti, F., 2017. Rainfall thresholds for possible landslide occurrence in Italy. Geomorphology 290, 39-57. https://doi.org/10.1016/j.geomorph.2017.03.031

Peruccacci, S., Brunetti, M.T., Luciani, S., Vennari, C., Guzzetti, F., 2012. Lithological and seasonal control on rainfall thresholds for the possible initiation of landslides in central Italy. Geomorphology 139-140, 79-90. https://doi.org/10.1016/j.geomorph.2011.10.005

Piciullo, L., Calvello, M., Cepeda, J.M., 2018. Territorial early warning systems for rainfall-induced landslides. Earth-Science Rev. 179, 228-247. https://doi.org/10.1016/j.earscirev.2018.02.013

Ponziani, F., Pandolfo, C., Stelluti, M., Berni, N., Brocca, L., Moramarco, T., 2012. Assessment of rainfall thresholds and soil moisture modeling for operational hydrogeological risk prevention in the Umbria region (central Italy). Landslides 9, 229-237. https://doi.org/10.1007/s10346-011$0287-3$

Sajeev, R., Praveen, K.R., 2014. Landslide Susceptibility Mapping on Macroscale along the Major Road Corridors in Idukki District, Kerala. Thiruvananthapuram, India.

Segoni, S., Piciullo, L., Gariano, S.L., 2018a. A review of the recent literature on rainfall thresholds 
Segoni, S., Rosi, A., Fanti, R., Gallucci, A., Monni, A., Casagli, N., 2018b. A regional-scale landslide warning system based on 20 years of operational experience. Water (Switzerland) 10, 1-17. https://doi.org/10.3390/w10101297

Segoni, S., Rosi, A., Lagomarsino, D., Fanti, R., Casagli, N., 2018c. Brief communication: Using averaged soil moisture estimates to improve the performances of a regional-scale landslide early warning system. Nat. Hazards Earth Syst. Sci. 18, 807-812. https://doi.org/10.5194/nhess-18$807-2018$

Song, S., Wang, W., 2019. Impacts of antecedent soil moisture on the rainfall- runoff transformation process based on high- resolution observations in soil tank experiments. Water (Switzerland) 11, 15-20. https://doi.org/10.3390/w11020296

Teja, T.S., Dikshit, A., Satyam, N., 2019. Determination of rainfall thresholds for landslide prediction using an algorithm-based approach: Case study in the Darjeeling Himalayas, India. Geosci. 9. https://doi.org/10.3390/geosciences9070302

Terlien, M.T.J., 1998. The determination of statistical and deterministic hydrological landslidetriggering thresholds. Environ. Geol. 35, 124-130. https://doi.org/10.1007/s002540050299

Tofani, V., Bicocchi, G., Rossi, G., Segoni, S., D’Ambrosio, M., Casagli, N., Catani, F., 2017. Soil characterization for shallow landslides modeling: a case study in the Northern Apennines (Central Italy). Landslides 14, 755-770. https://doi.org/10.1007/s10346-017-0809-8

Uchimura, T., Towhata, I., Anh, T.T.L., Fukuda, J., Bautista, C.J.B., Wang, L., Seko, I., Uchida, T., Matsuoka, A., Ito, Y., Onda, Y., Iwagami, S., Kim, M.S., Sakai, N., 2010. Simple monitoring method for precaution of landslides watching tilting and water contents on slopes surface. Landslides 7, 351-357. https://doi.org/10.1007/s10346-009-0178-Z

Uchimura, T., Towhata, I., Wang, L., Nishie, S., Yamaguchi, H., Seko, I., Qiao, J., 2015. Precaution and early warning of surface failure of slopes using tilt sensors. Soils Found. 55, 1086-1099. 
https://doi.org/10.1016/j.sandf.2015.09.010

United Nations Development Programme, 2018. Kerala Post Disaster Needs Assessment Floods and Landslides-August 2018. Thiruvananthapuram, India.

Valenzuela, P., Domínguez-Cuesta, M.J., Mora García, M.A., Jiménez-Sánchez, M., 2018. Rainfall thresholds for the triggering of landslides considering previous soil moisture conditions (Asturias, NW Spain). Landslides 15, 273-282. https://doi.org/10.1007/s10346-017-0878-8

Varnes, D., 1978. Slope Movement Types and Processes. Transp. Res. Board Spec. Rep.

Wei, X., Fan, W., Cao, Y., Chai, X., Bordoni, M., Meisina, C., Li, J., 2020. Integrated experiments on field monitoring and hydro-mechanical modeling for determination of a triggering threshold of rainfall-induced shallow landslides. A case study in Ren River catchment, China. Bull. Eng. Geol. Environ. 79, 513-532. https://doi.org/10.1007/s10064-019-01570-7

Wicki, A., Lehmann, P., Hauck, C., Seneviratne, S.I., Waldner, P., Stähli, M., 2020. Assessing the potential of soil moisture measurements for regional landslide early warning. Landslides 17, 1881-1896. https://doi.org/10.1007/s10346-020-01400-y

Wu, M.H., Wang, J.P., Chen, I.C., 2019. Optimization approach for determining rainfall durationintensity thresholds for debris flow forecasting. Bull. Eng. Geol. Environ. 78, 2495-2501. https://doi.org/10.1007/s10064-018-1314-6

Yang, Z., Cai, H., Shao, W., Huang, D., Uchimura, T., Lei, X., Tian, H., Qiao, J., 2019. Clarifying the hydrological mechanisms and thresholds for rainfall-induced landslide: in situ monitoring of big data to unsaturated slope stability analysis. Bull. Eng. Geol. Environ. 78, 2139-2150. https://doi.org/10.1007/s10064-018-1295-5

Zhao, B., Dai, Q., Han, D., Dai, H., Mao, J., Zhuo, L., 2019a. Probabilistic thresholds for landslides warning by integrating soil moisture conditions with rainfall thresholds. J. Hydrol. 574, 276287. https://doi.org/10.1016/j.jhydrol.2019.04.062

Zhao, B., Dai, Q., Han, D., Dai, H., Mao, J., Zhuo, L., Rong, G., 2019b. Estimation of soil moisture 
using modified antecedent precipitation index with application in landslide predictions. 


\section{$1 \quad$ Usage of antecedent soil moisture for improving the performance of rainfall}

$$
\text { thresholds for landslide early warning }
$$

\section{Minu Treesa Abraham ${ }^{1}$, Neelima Satyam ${ }^{1}$, Ascanio Rosi ${ }^{2}$, Biswajeet Pradhan ${ }^{3,4,5,6^{*}}$ and}

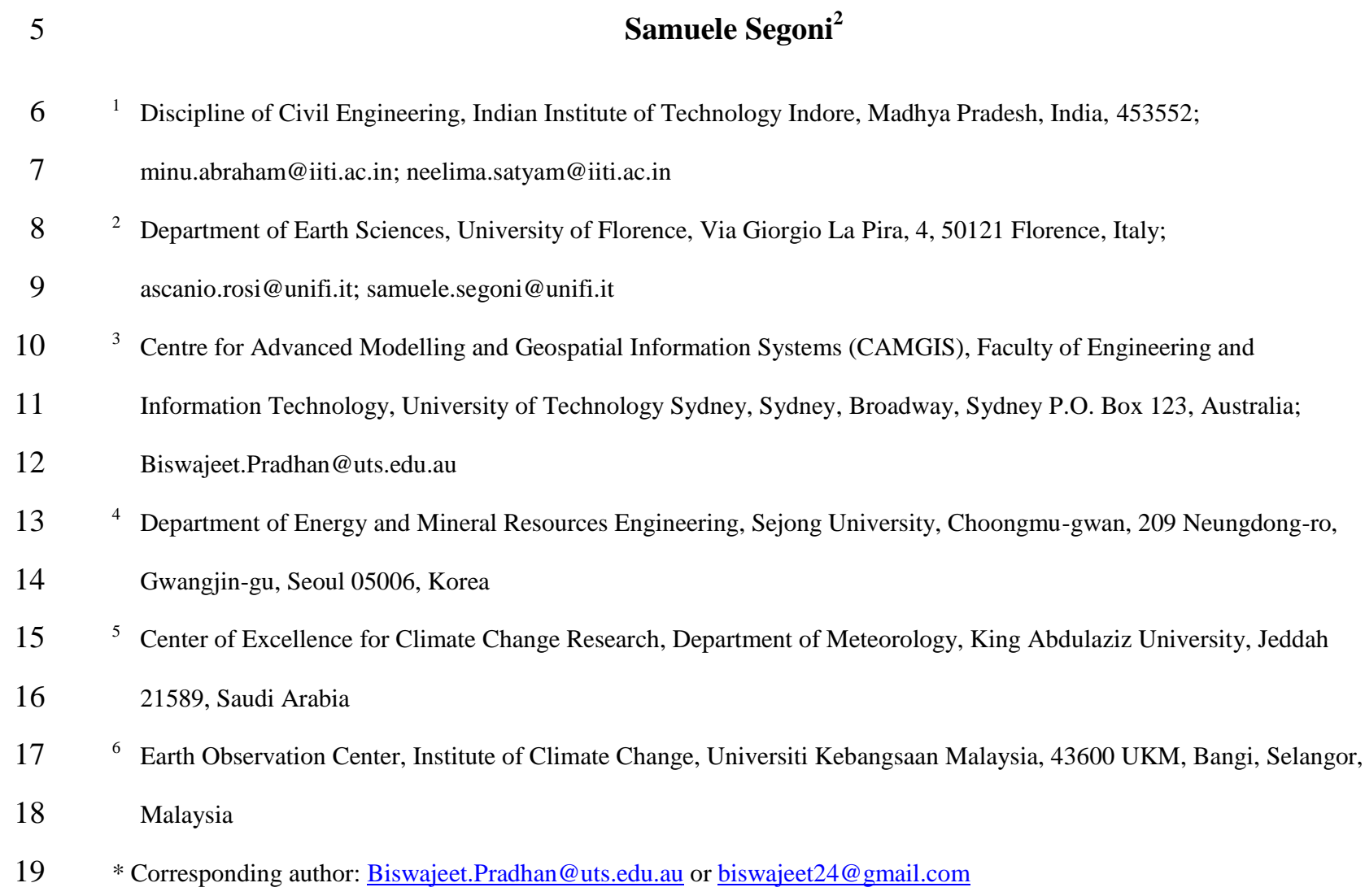

4 Department of Energy and Mineral Resources Engineering, Sejong University, Choongmu-gwan, 209 Neungdong-ro,

14 Gwangin-gu, Seoul 05006, Korea

155 Center of Excellence for Climate Change Research, Department of Meteorology, King Abdulaziz University, Jeddah

176 Earth Observation Center, Institute of Climate Change, Universiti Kebangsaan Malaysia, 43600 UKM, Bangi, Selangor,

19 *Corresponding author: Biswajeet.Pradhan@uts.edu.au or biswajeet24@ gmail.com

1621589 , Saudi Arabia

\section{Abstract}

Landslides triggered by heavy rains are increasing in number and creating severe losses in hilly regions across the world. Rainfall thresholds on regional and local-scales are being used for forecasting such events, for efficient early warning. Empirical and probabilistic approaches for defining rainfall thresholds are traditional tools which are being used as part of the forecasting system for rainfall induced landslides. Such methods are easy-to-use and are based on statistical analyses. They can be derived without looking into the complex hydro-geological processes involved in slope failures, but are often associated with the disadvantage of higher false alarms, limiting their 
applications in a regional landslide early warning system (LEWS). This study is an attempt to improve the performance of conventional meteorological thresholds by considering the effect of soil moisture, using a probabilistic approach. Idukki district in southern part of India is highly susceptible to landslides and has witnessed major socio-economical setbacks in the recent disasters happened in 2018 and 2019. This tourist hub is now in need of a landslide forecasting system, which can help in landslide risk reduction. This study attempts to understand the effect of averaged soil moisture estimates derived from passive microwave remote sensing data, for improving the performance of conventional empirical and probabilistic thresholds. For defining empirical thresholds, an algorithmbased approach such as Calculation of Thresholds for Rainfall-induced Landslides Tool (CTRL-T) has been used. Probabilistic thresholds were defined using a Bayesian approach, finding the posterior probability of occurrence using the marginal and conditional probabilities of the control parameters along with the prior probability of occurrence of landslide. The derived rainfall thresholds were quantitatively compared with the Bayesian probabilistic threshold derived using rainfall severity and soil wetness using an area under the curve (AUC) based receiver operating characteristics (ROC) curve method. The results show that when the antecedent moisture content in soil is less, only severe rainfall events can trigger landslides in the study area; while less severe rainfall events can also trigger landslides when the soil is wet. The role of soil wetness in the initiation is used to improve the performance of the conventional methods, and a ROC approach was used for the statistical comparison of different models. Further, the results indicated that the probabilistic threshold using rainfall severity and soil wetness outperformed the conventional approaches with AUC of 0.96, being the most sensitive and specific among the models considered. This result opens new promising perspectives for the development of an operational LEWS in the Idukki district based on a combination of rainfall and soil moisture data. Moreover, this work contributes to strengthen the advancing trend of hydro-meteorological thresholds based on soil moisture, which is gaining a growing attention in landslide studies and that, to date, was lacking evidences in monsoon regions.

Keywords: landslides; rainfall thresholds; LEWS; soil moisture; Idukki 
Forecasting landslides and evacuating people from hazardous zones is an important risk reduction strategy (Althuwaynee and Pradhan, 2017). Considering the climate change and associated extreme rainfall phenomenon, the number of rainfall-induced landslides are expected to rise (Alvioli et al., 2018; Chen et al., 2019; Gariano and Guzzetti, 2016). Being a geomorphological process in the landscape evolution (Iida, 1999), the detailed understanding of slope failure mechanisms involves hydrological studies and forecasting of possible failure planes (Agostini et al., 2014) using relevant geotechnical and meteorological parameters. However, these parameters are highly site specific and often difficult to determine with the desired accuracy (Tofani et al., 2017), except that for single slopes or very small basins (Chae et al., 2017), and sophisticated experimental research is required for understanding the mechanism in detail (Kim et al., 2018). Hence, a more practiced approach is needed to forecast the critical conditions which result in the occurrence of landslides using the primary triggering factor i.e. rainfall - with the aid of rainfall thresholds (Caine, 1980; Keefer et al., 1987; Piciullo et al., 2018). Rainfall thresholds can be empirical, probabilistic, or algorithm based (Althuwaynee et al., 2015; Piciullo et al., 2018; Segoni et al., 2018a). All the approaches exploit historical data to find a mathematical relationship between rainfall and the occurrence of landslides in a region, to identify critical rainfall conditions which can trigger landslides in the future. A rainfall event is most commonly characterised in terms of cumulated rainfall event (E), duration (D), and intensity (I) (which are referred to as "rainfall parameters"). Consequently, the thresholds are often defined as cumulated event rainfall vs. duration (ED thresholds) (Lainas et al., 2016; Melillo et al., 2018, 2016; Peruccacci et al., 2017; Teja et al., 2019) or as rainfall intensity vs. duration (ID thresholds) (Battistini et al., 2017; Brunetti et al., 2010; Guzzetti et al., 2008; Lainas et al., 2016; Wu et al., 2019).

When the definition of thresholds is associated with the generation of many false alarms, their usage in operational Landslide Early Warning System (LEWS) may be inappropriate (Aleotti, 2004; Guzzetti et al., 2008; Kirschbaum et al., 2012; Segoni et al., 2018b). Low performances of rainfall thresholds are traditionally related to the uncertainties associated with the definition of rainfall 
parameters, the quality and resolution of the historical data and the intrinsic limitations of the statistical models (Gariano et al., 2020; Marra et al., 2017; Nikolopoulos et al., 2014).

Some authors argued that sometimes the statistical correlation between rainfall parameters and landslide initiation is too weak and that hydro-meteorological thresholds accounting for both rainfall and hydrological (e.g. soil moisture) parameters could provide a stronger and more accurate assessment (Bogaard and Greco, 2018; Jakob et al., 2006; Terlien, 1998). Integrating soil moisture with rainfall thresholds has been proven effective in improving the rainfall thresholds (Abraham et al., 2020b; Segoni et al., 2018c; Zhao et al., 2019a), as the antecedent moisture content plays a key role in the shear strength parameters of soil. The soil moisture conditions play a key role in the infiltration process (Song and Wang, 2019) which significantly influences the initiation of landslides (Alimohammadlou et al., 2014; Baum et al., 2008; Bicocchi et al., 2019; Iverson, 2000; Wei et al., 2020; Yang et al., 2019). Weighted indexes (Glade et al., 2000; Ponziani et al., 2012); and satellite data (Zhao et al., 2019b) can be used for estimating soil moisture values when real-time field monitoring (Abraham et al., 2020c; Dikshit et al., 2018; Uchimura et al., 2015, 2010) cannot be conducted. Hydrological models (Abraham et al., 2020b; Zhao et al., 2019a) can also be used for the estimation of soil moisture content. In the published literature, soil moisture combined with rainfall thresholds has been tested mainly in Mediterranean, temperate and alpine climatic settings, whereas in monsoon regions similar types of tests are almost completely missing (Jakob et al., 2006; Mirus et al., 2018a; Valenzuela et al., 2018; Wicki et al., 2020).

The present work attempts to define statistical rainfall thresholds in Idukki district (India) and to improve their effectiveness by coupling rainfall parameters with soil moisture data. First, ED thresholds are defined using an automatic algorithm-based approach (Melillo et al., 2014). The based on the location and time. After identifying the triggering rainfall event, the algorithm defines 
110 probabilistic approach (Berti et al., 2012), the effect of event rainfall, duration and intensity on the

111 occurrence of landslides is evaluated (probabilistic rainfall thresholds). Both empirical (Melillo et al., 112 2018, 2016; Peruccacci et al., 2017) and probabilistic approaches (Berti et al., 2012; Dikshit and 113 Satyam, 2019) were considered to establish the relationship between primary triggering factor 114 (rainfall) and the result (landslide), and these are simple statistical approaches that are easy to derive by integrating with a rainfall forecasting system. Similar studies have been conducted for Indian Himalayas (Abraham et al., 2020a; Dikshit and Satyam, 2018, 2019; Teja et al., 2019) and the Western Ghats (Abraham et al., 2020e, 2019); however, these methods were not always found to be operational due to a higher number of false alarms or missed alarms, limiting their applications in LEWS. This study aims to overcome these limitations by integrating soil moisture data along with the rainfall thresholds. The objective is to find if the addition of soil moisture data can perform better than the conventional methods based on the rainfall data alone.

\section{Description of the study area}

The Western Ghats of Indian Peninsula is highly susceptible to rainfall-induced landslides. There is a surge in the number of landslides during monsoon season since 2018, due to very-high intensity rainfalls. The landslides and floods happened in 2018 severely affected the south Indian states of Kerala and Karnataka. Among the 14 districts in the state of Kerala, 13 are part of the Western Ghats and are susceptible to landslides. Nearly 5.3 million people in the state were affected by the disaster in 2018 (United Nations Development Programme, 2018). The Western Ghats scarps, running the whole extent of the mountain range, are highly prone to landslides. Very-high intensity rainfall, along with the anthropogenic activities, has accelerated the geological processes leading to landslides, making the situation alarming (Kuriakose et al., 2009b).

Idukki is a hilly district in the Western Ghats and is the second largest district in the state of Kerala, in terms of area. This district covers an area of $4358 \mathrm{~km}^{2}$ and derived its name from the word 'Idukku' in the vernacular dialect meaning narrow gorge. This itself indicates the geography of the area. The district is the major power source of Kerala and houses many hydroelectric projects, including the famous arch dam of Idukki. About 50\% of the district is covered by forests and Idukki is drained by 
three major rivers, two flowing westward and one eastward. The rainfall across the district is varying with the least values recorded in the northern side with a long-term average of $1000 \mathrm{~mm}$ while the southern parts record an average rainfall of $5000 \mathrm{~mm}$ (Sajeev and Praveen 2014; Department of Mining and Geology 2016). The southwest monsoon season from June to September contributes 60\% of the annual rainfall and around $24 \%$ is contributed by the North-East monsoon from October to December. Due to varying topography, the climatic conditions in the hill ranges, plateaus and midlands of the district are different from each other.

Fig. 1. Location details of study area. (a) India, and (b) Digital Elevation Model of Idukki (modified using CartoDEM (CartoDEM, 2015)) along with location of rain gauges.

Geologically, Idukki can be divided into three different parts from south to north. The charnockite rocks in the south, migmatitic complex in central portion, and peninsular gneissic complex in the northern part. Granite gneiss is the oldest and predominant group among the peninsular gneissic complex while the charnockite group consists of magnetite quartzite, pyroxene granulite and charnockite (Department of Mining and Geology 2016). Structural cum denudational hills are the predominant geomorphological feature of Idukki. The hills are generally having a thin soil cover overlaid on Precambrian basement rocks. The midlands have a rugged topography with small hills and deep valleys with an average elevation of $50 \mathrm{~m}$. The zone where midlands grades to plateaus are called the foothills, ranging up to $8 \mathrm{~km}$ in width. A major portion of the district belongs to the plateau region, with a large landmass of moderate slope. The elevation of the plateau region goes up to 1500 $\mathrm{m}$, and the regions at an elevation greater than $1500 \mathrm{~m}$ belong to hilly ranges. More than $50 \%$ of the study area is covered by forest loam soils, produced by the weathering of rock under thick forest cover. The midlands are covered by lateritic soil with high permeability and less organic content. The valley portion of the terrain are covered with fine particles of sandy loam to clay type, formed by sedimentation and transportation of hill slopes. The narrow riverbanks consist of fertile alluvial soil and are more common in the midlands.

Because of its topographic variability and heavy rainfall, the district is highly susceptible to rainfall induced landslides. The typology of landslides in the Western Ghats includes earth and debris slides, 
rock falls, creep, slump and debris flows (Abraham et al., 2020d). Due to the thin regolith layer, shallow landslide (Varnes, 1978) is the most common type during prolonged rainfalls (Kuriakose et al., 2009a). Idukki district in particular is mostly affected by the cut slope failures along the major road corridors, disrupting the transportation network in the district. Recent changes in the land use patterns for infrastructure development and agriculture have affected the stability of slopes of this ecologically sensitive zone (Gadgil et al., 2011) and has aggravated the number of landslide disasters (Kuriakose et al., 2009b). Hence the development of an effective regional scale LEWS is highly needed to forecast the future landslides in the region.

\section{Data and Methodology}

The study explores the possibility of using soil moisture data in improving the performance of statistical thresholds. The overall methodology flow chart adopted in this study is shown in Fig 2 . The methodology involves data collection from multiple sources, the definition of thresholds and their performance evaluation using different skill scores. For the analysis, historical rainfall, landslide, and soil moisture data were collected. For developing empirical and probabilistic rainfall thresholds, only rainfall and landslide data are required, while for developing probabilistic rainfall thresholds based on rainfall severity and soil wetness (RS threshold), the soil moisture data were integrated with empirical ED thresholds using a probabilistic approach. While the empirical threshold considers the effect of rainfall events which resulted in landslides, the probabilistic thresholds consider both triggering and non-triggering rainfall events for the analysis.

Fig. 2. Methodology of study.

\subsection{Data collection}

The dataset used for this study spans from 2010 to 2018 and the historical data from this period was used to derive the empirical and probabilistic thresholds for occurrence of landslides in Idukki district. 
189 The daily rainfall data was collected from the Indian Meteorological Department (India 190 Meteorological Department 2019) for four rain gauges within the district. The landslide data was 191 collected from various government agencies and media reports (Abraham et al., 2019) and only landslides for which the date of occurrence was available were used for the analysis. For each rain gauge a reference area was defined and multiple landslides triggered in the same day in each area were considered as one landslide event and rainfall data were collected from the reference rain gauge. By these criteria, 225 landslide events were identified in the study area which were first used as the input for empirical thresholds. For probabilistic thresholds, a total of 5028 rainfall events recorded by the four rain gauges during the study period were considered.

The average daily soil moisture data was collected from Giovanni's website by National Aeronautics and Space Administration Goddard Earth Sciences Data and Information Services Center (NASA GES DISC) (de Jeu and Owe, 2014, 2012; Giovanni, 2020). The data was derived using land parameter retrieval model (LPRM), which is a multi-parameter retrieval algorithm focused on hydrological and climate studies. It retrieves the soil moisture from the microwave observations from sensors. The observed brightness temperatures were used to derive the soil moisture data, using LPRM (Owe et al., 2008). LPRM is based on a forward radiative transfer model and the output is the volumetric soil moisture content in percentage. The soil moisture on the day before the occurrence of landslide, termed as the 'antecedent soil moisture' was used for the analysis in this research. The spatial resolution of the data is $0.25^{\circ} \times 0.25^{\circ}$. The study area (Idukki district) consists of 14 grids of size $0.25^{\circ} \times 0.25^{\circ}$ (Figure 1). After calculating the area of Idukki within each grid, the weighted average was calculated for the whole area, for simplified calculation. This value is called the

210 'averaged moisture content'. Another term, 'soil wetness' is introduced, to represent a range of 211 antecedent soil moisture, on a scale of 0 to 1 . The soil wetness values were divided into five equal 212 parts, representing different ranges of moisture content. This classification is used to overcome the 213 limitations associated with using averaged data for a larger area. The value of soil wetness is directly 214 proportional to the moisture content values and indicates the wetness of soil before the landslide. 
215 Thus, by using historical rainfall, landslide and soil moisture data, thresholds were defined using

216 multiple approaches for the study area to find the effect of soil moisture on the forecasting 217 performance of the thresholds.

\subsection{Empirical thresholds}

The selection of rain gauges and rainfall parameters plays a critical role in the definition of rainfall thresholds (Abraham et al., 2020e). For the study area, rainfall data from the four available rain gauges were considered for the analysis. The intensity-duration thresholds for the study area was earlier derived from using a nearest rain gauge approach (Abraham et al., 2019), considering 225 landslide events occurred from 2010 to 2018. From the pioneering work of Caine (Caine, 1980), ID thresholds were defined for regions across the globe (Abraham et al., 2020c, 2019; Brunetti et al., 2010; Dikshit and Satyam, 2018; Guzzetti et al., 2008, 2007; Segoni et al., 2018a). Even though intensity can easily be converted to event rainfall and vice-versa, recent literature shows a shift towards defining ED thresholds instead of ID thresholds (Melillo et al., 2018, 2014; Peruccacci et al., 2012; Teja et al., 2019; Zhao et al., 2019a). The reason is that E and D are two mutually independent parameters while $\mathrm{I}$ is a function of $\mathrm{D}$ and $\mathrm{E}$. Hence, for a definition of rainfall thresholds and rainfall severity, the data points on ED plane was considered in this study. In this study, the reconstruction of event- duration thresholds was carried out by using Calculation of Thresholds for Rainfall Induced Landslides - Tool (CTRL-T) (Melillo et al., 2018, 2014). CTRL-T uses an algorithm-based approach, extracting the rainfall events automatically from the daily precipitation data input. From the extracted events, rainfall conditions that have triggered landslides were identified; and used to derive the rainfall thresholds for the region. The tool considers a buffer zone around each landslide location, to search for the rain gauge and identify the triggering event. In this study, a search radius of $20 \mathrm{~km}$ is considered, due to the low rain gauge density in the study area. The algorithm also considers a delay time between the end of rainfall and occurrence of landslide. In this study, the delay time is taken as 48 hours (Melillo et al., 2014). If no rainfall condition is recreated within this delay time before the occurrence of landslide, the event will be discarded by the algorithm. The algorithm first determines 
the total event rainfall and duration of rainfall for all identified rainfall events and then to minimise

243 the effect of spatial variability of rainfall distribution, single or multiple rainfall conditions (MRC)

244 likely to result in failures and a weight is assigned to each of them. Then for each landslide, the

245 highest weight was used to identify the reference rain gauge and to choose the maximum probable

246 rainfall conditions (MPRC). In this study, five different threshold lines were defined using CTRL-T,

247 at different exceedance probabilities of $1 \%, 5 \%, 10 \%, 20 \%$ and $50 \%$ (termed as $\mathrm{T}_{1}, \mathrm{~T}_{5}, \mathrm{~T}_{10}, \mathrm{~T}_{20}$ and

$248 \mathrm{~T}_{50}$, respectively). Thresholds and related uncertainties were estimated from MPRCs. The defined

249 thresholds are in the form of a power law, determined using the frequentist approach (Brunetti et al.,

250 2010) and can be expressed as:

$$
E=(\alpha \pm \Delta \alpha) D^{(\gamma \pm \Delta \gamma)}
$$

where, $\alpha$ is the scaling parameter or the intercept and $\gamma$ is the shape parameter which denotes the slope of the equation. $\Delta \alpha$ and $\Delta \gamma$ represents the uncertainties associated with $\alpha$ and $\gamma$, respectively. The uncertainties are determined using a bootstrap approach.

\subsection{Probabilistic approach}

The empirical thresholds compare an input value with the defined thresholds and will have a single output (triggering or non-triggering). It is often difficult to decide the exceedance probability to be selected as a threshold beyond which a radical change can be expected in the system (Berti et al., 2012). The discretion between triggering and non- triggering rainfall conditions is not trivial in such cases. To derive the equation, only the triggering rainfall conditions are considered. This increases the chances of false alarms, as numerous rainfall events that cross the threshold line not necessarily trigger landslides.

By considering both triggering and non- triggering rainfalls for analysis, probability-based models are more informative and provide a better option to find extreme events. In this study, a Bayesian approach is used to define probabilistic thresholds (Berti et al., 2012). 
268 Bayes theorem applies a conditional probability of some event $L$ (landslide) given the occurrence of 269 another event $X$ (rainfall, expressed in terms of $\mathrm{E}$, I or D). This is also called the posterior probability, $270 \quad P(X \mid L)$. It can be calculated as follows (Berti et al., 2012):

$$
P(L \mid X)=\frac{P(X \mid L) * P(L)}{P(X)}
$$

where, $P(X \mid L)$ is the conditional probability of occurrence of rainfall of magnitude $X$, when a landslide occurs. This is also called as a likelihood.

$P(L)$ is the prior probability of occurrence of landslide regardless of the occurrence rainfall magnitude.

$P(X)$ is the marginal probability of $X$, which can be defined as the probability of occurrence of rainfall regardless of the occurrence of landslides. The terms can be calculated mathematically using relative frequencies. Let $N_{R}$ be the total number of rainfall events during study period, $N_{L}$ be the total number of landslides occurred, $N_{X}$ be the number of rainfall events with magnitude $X$ and $N_{(X \mid L)}$ be the number of rainfall events with magnitude $X$ that resulted in landslides. The probabilities can be computed as (Berti et al., 2012):

$$
\begin{gathered}
P(L) \approx \frac{N_{L}}{N_{R}} \\
P(X) \approx \frac{N_{X}}{N_{R}} \\
P(X \mid L) \approx \frac{N_{(X \mid L)}}{N_{L}}
\end{gathered}
$$


282 Considering the rainfalls that resulted in landslides only will give us partial information, the

283 likelihood. To understand the influence of rainfall of magnitude $X$, it is important to compare the prior

284 probability with the posterior probability.

\subsubsection{Two-dimensional analysis}

Two-dimensional case is the extension of Eq. 2 by considering two conditions $X, Y$ instead of the single condition $X$ in Eq. 2. In the initial analysis, we consider $X$ and $Y$ as magnitude of two rainfall parameters (E,D ; I,D; E,I). The calculation of prior, marginal and conditional probabilities are given below:

$$
\begin{gathered}
P(L \mid X, Y)=\frac{P(X, Y \mid L) * P(L)}{P(X, Y)} \\
P(L) \approx \frac{N_{L}}{N_{R}} \\
P(X, Y) \approx \frac{N_{X, Y}}{N_{R}} \\
P(X, Y \mid L) \approx \frac{N_{(X, Y \mid L)}}{N_{L}}
\end{gathered}
$$

291 The study explores the effect of antecedent soil moisture content using a two-dimensional 292 probabilistic analysis. During the second phase, we considered rainfall severity in ED plane and soil wetness as $X$ and $Y$, respectively. Based on the values of soil wetness, five different categories were considered for analysis viz, less than $0.2,0.2$ to $0.4,0.4$ to $0.6,0.6$ to 0.8 , and 0.8 to 1 . The categories based on rainfall severity were less than $T_{1}, T_{1}$ to $T_{5}, T_{5}$ to $T_{10}, T_{10}$ to $T_{20}, T_{20}$ to $T_{50}$ and greater than

$296 \mathrm{~T}_{50}$. Thus, the two-dimensional plane was divided into 30 cells as a 6 x 5 matrix as shown in Fig. 6.

297 These values were used for the definition of RS threshold. 


\section{Results}

\subsection{Empirical thresholds}

CTRL-T tool considered 177 landslide events out of the 225 and the rest were discarded to avoid introduction of relevant spatio-temporal uncertainties in the analysis. The uncertainties are associated with the less rain gauge density in the study area. As described earlier, the landslides for which responsible rainfall conditions were not identified were discarded. This can be due to a distance more than $20 \mathrm{~km}$ between the location of rain gauges and landslide or due to a delay time more than 48 hours after the end of any rainfall event. The algorithm forecasted rainfall thresholds with various exceedance probability both in normal and logarithmic plot (Fig. 3). The threshold lines of 1\%, 5\%, $10 \%, 20 \%$ and $50 \%$ exceedance probabilities were used to classify the events into six categories based on the severity of rainfall. These lines are named $T_{1}, T_{5}, T_{10}, T_{20}$ and $T_{50}$, respectively. The slope of threshold lines in logarithmic plot was found to be $0.57 \pm 0.03$. This value is not in good agreement with the ID thresholds defined for the area in a previous study (Abraham et al., 2019). Though both the studies used frequentist approach for the definition of thresholds, the process of identification of responsible rainfall event was different. In the previous study (Abraham et al., 2019), the responsible rainfalls were identified using a Thiessen polygon approach manually, while in this study, the automatic algorithm, CTLRL-T is used for identifying the responsible rainfall event. The parameters of threshold lines and the uncertainties associated are listed in Table 1.

Table 1. Values of $\alpha, \gamma$ and the uncertainties associated with different exceedance probabilities be reliable, the relative uncertainty $(\Delta x / x$ for any variable $x$ ) should be less than $10 \%$. Here the 
relative uncertainty of $\gamma$ is $5.2 \%$. But with higher exceedance probabilities, the relative uncertainty of $\alpha$ is crossing this limiting value.

With 5\% exceedance probability, $20.19 \mathrm{~mm}$ rainfall can trigger a landslide in the region for a duration of 24 hours and when the duration is 624 hours, a rainfall of $129 \mathrm{~mm}$ can trigger landslides in the region. For a better understanding of the effect of each rainfall parameter on the occurrence of landslides, probabilistic rainfall thresholds were defined for the area.

\subsection{Probabilistic thresholds}

The maximum probable rainfall conditions which were used for the definition of ED thresholds were considered as the triggering rainfall events for the probabilistic analysis. Thus, out of the 5028 rainfall events considered, 177 events were identified as triggering events by CTRL- T algorithm and the rest 4851 events were considered as non-triggering rainfall events. In the one-dimensional case, six categories of rainfall duration, five categories of cumulated rainfall event and seven categories of rainfall intensity were considered. The results are plotted in Fig. 4 (a-f); where Fig. 4a, c and e depict the prior probability, marginal probability and likelihood, and Fig. $4 \mathrm{~b}, \mathrm{~d}$ and $\mathrm{f}$ depict the prior and posterior probabilities. The variable $X$ in Eq. (2-5) is replaced with $\mathrm{D}, \mathrm{E}$ and $\mathrm{I}$ in the respective graphs. $P(L)$ being a constant parameter (value 0.035 in this study), the ratio of $P(X \mid L)$ to $P(X)$ determines the variation of posterior probability values. Hence when $P(X \mid L)>P(L)$, the posterior probability is greater than prior probability and vice versa. The more the variation between prior and posterior probability, the more significant the variable is. It can be seen, that for duration and event rainfall, for the largest values of variables, the values of $P(L \mid X)$ is less than $P(L)$, while in the case of intensity, high intensity rainfalls are more probable to trigger landslides in the region. The plots of $P(X)$ and $P(X \mid L))$ are well above the plot of prior probability in all the cases. Intensity was found to be the most significant variable, with the maximum ratio between posterior and prior probabilities. The maximum posterior probability when the control parameter is $\mathrm{D}$ was found to be 0.053 where the value is 0.103 and 0.116 in the case of $\mathrm{E}$ and I, respectively. Maximum probability occurs when the duration is between $120 \mathrm{~h}$ to $240 \mathrm{~h}$; event rainfall is between $100 \mathrm{~mm}$ to $200 \mathrm{~mm}$; and intensity is greater than $3 \mathrm{~mm} / \mathrm{h}$. 
351 Fig. 4. Prior, conditional, marginal and posterior probabilities with respect to rainfall parameters. (a,

b) Duration; (c, d) Event rainfall; and (e, f) Intensity.

353 To evaluate the joint occurrence of two parameters, two-dimensional Bayesian analysis were 354 conducted with data on three different planes (Fig. 5). The two-dimensional space for each analysis 355 was divided into small cells based on the categories of parameters used for one-dimensional analysis. 356 Hence the ID plane is a $7 \times 6$ matrix, ED plane is a $5 \times 6$ matrix and the EI plane is a $5 \times 7$ matrix. 357 There are several no data points in all three cases, due to the lower number of landslides considered for the analysis. As identified from the one-dimensional analysis, E and I were found to be more critical parameters than D. This is the reason why this study has considered all three different combinations of the control parameters even though the empirical thresholds are defined on ED plane only. The maximum probability value was obtained on EI plane, when the intensity value is less than $0.5 \mathrm{~mm} / \mathrm{h}$ and event rainfall is between $100 \mathrm{~mm}$ to $200 \mathrm{~mm}$, with a value of 0.54 .

Fig. 5. Two-dimensional posterior probabilities of occurrence of landslide on (a) ID plane, (b) ED plane, and (c) EI plane.

It is evident from Fig. 6 that even less severe rainfall events when falling on a moist soil can trigger landslides in the region. Most of the landslides for which rainfall events were less severe happened on days with higher soil wetness. Also, when the rainfall event is severe, even dry soil can be susceptible to landslides. The maximum probability of 0.49 was observed when the rainfall severity was between $\mathrm{T}_{20}$ to $\mathrm{T}_{50}$ and the soil wetness was between 0.8 to 1 . With the available data, when the antecedent soil moisture is less, only extremely severe rainfall conditions can trigger landslides in the area. This affects the performance of the ED thresholds considerably. For different antecedent soil moisture conditions, this makes it easier to decide the threshold line to be used. 
Fig. 6. Two-dimensional Bayesian probabilities for occurrence of landslides based on rainfall severity and soil wetness.

\section{Discussions}

To verify the performance of all models and to understand which model is performing better for the study area, different thresholds should be compared quantitatively (Lagomarsino et al., 2015). In this study, empirical thresholds on ED plane, probabilistic thresholds on all three combinations of control parameters (ED, ID and EI) and also a two-dimensional Bayesian approach by combining empirical ED thresholds with soil moisture have been derived. The maximum probability value obtained in the two-dimensional analysis was in the case of EI thresholds, and the value is 0.54 . The value was obtained when the intensity is less than $0.5 \mathrm{~mm} / \mathrm{h}$ and event rainfall is between 100 to $200 \mathrm{~mm}$. This implies a prolonged duration of 8 days or more. The intensity value is too low in this case, yet the probability value is the maximum. The definition of 2-dimensional Bayesian probability majorly depends upon the relative occurrence of landslides when the rainfall conditions are satisfied and the occurrence of rainfall events with specified conditions. The number of events with the specified EI conditions were less, but more than half of them have resulted in landslides based on the historical data. Thus, the probability of occurrence of landslides is higher in this case. This result points towards the significance of using a physical parameter such as soil moisture for the definition of threshold. The top regolith layer throughout the district consists of forest loam, lateritic soil, alluvial soils etc, with higher fine fraction (Department of Mining and Geology Kerala, 2016). The less permeable soil has a higher water holding capacity and the moisture content increases when the rainfall is continuous. The prolonged rainfall has thus reduced the shear strength of soil and the landslide has happened at a very less intensity value. This complicated process is simplified by using a statistical approach, by considering the effect of soil wetness. To understand the performance of such a model with respect to the meteorological thresholds, a quantitative comparison is required.

An ROC curve approach was used for quantitative comparison. ROC curve is a tool to understand the performance of a model with a binary outcome. Each threshold value can forecast two outcomes for a day; 'landslides' or 'no landslides. If the threshold condition is crossed, the model forecasts 
'landslides' and otherwise, 'no landslides. When the forecasting is correct and landslide occurs, it is termed as a true positive $(T P)$. Another possibility of correct outcome is the result 'no landslides' on a day in which landslides do not occur. This can be counted as a true negative (TN) result. When the forecasting goes wrong, it also has two possible outcomes. 'Landslides' forecasted on a non-landslide day, which is a false positive $(F P)$ or simply a false alarm and 'no landslides' forecasted on a day in which landslides occur, termed as false negatives $(F N)$ or missed alarms. A perfect model should only have true outcomes, without any false alarms or missed alarms.

A ROC curve is a plot with a false positive rate of a model on x-axis and a true positive rate on y axis. It evaluates the overall performance of the model. The true positive rate is also called the sensitivity of the model. It provides the proportion of landslide occurrences which are correctly identified $(T P /(T P+F N))$. The specificity of a model is the true negative rate and is the ratio of $T N$ to the sum of $T N$ and $F P$. The false positive rate can be calculated by subtracting specificity value from 1 . An ideal model is expected to have both sensitivity and specificity values as 1 . Hence the point $(0,1)$ on ROC curve is called the perfect point. Points which are closer to this perfect point has a better performance. Also, the model with better performance is the one with a maximum area under the curve (AUC) among the different models considered. Threat score and True Skill Statistic (TSS) are two other parameters which were used to understand the performance of a model (Mirus et al., 2018b). Threat score is defined as the ratio of $T P$ to the sum of $T P, F P$ and $F N$. TSS is the difference between sensitivity and false positive rate. For an ideal model, the value of both these variables should be 1 .

ROC curves for all models considered in the study are plotted in Fig. 7 and the statistical attributes are listed in Table 2. From Fig. 7, it can be observed that the RS threshold covers the maximum area in the plane with an AUC of 0.96. The empirical ED threshold has the second highest AUC of 0.86. All the three probabilistic rainfall thresholds have very close AUC values as observed in Fig. 7. EI threshold covers a larger area than the other two, indicating its better performance in comparison with the other two probabilistic rainfall thresholds. The distance from perfect point is minimum in the case of RS thresholds, in the case of critical probabilities 0.1 and 0.15 . It can also be observed that the 
value of threat score and TSS are maximum in the case of RS thresholds. The maximum value of

430 threat score is obtained as 0.24 and TSS as 0.90 , both in the case of RS thresholds with critical

431 probability 0.1 , which is also the closest one to the perfect point.

432 Fig. 7. ROC curves for the derived thresholds. Sensitivity is the ability of a model to correctly identify the landslide events and Specificity is the ability to correctly identify the non-landslide events

Looking into the details in Table 2, it confirms with the literature as the empirical thresholds result in many false alarms, making it inadequate to use in an LEWS. The number of false alarms can considerably be reduced by using probabilistic rainfall thresholds, as listed in Table 2 . The number of $F P$ in the case of probabilistic ED. ID and EI are much lesser than the other two models considered. But this reduction in false alarms comes with the cost of a higher number of missed alarms $(F N)$. While 171 landslide events out of the 177 events are correctly forecasted by the empirical ED threshold line $\mathrm{T}_{1}$, and 172 are correctly forecasted by RS threshold when the critical probability is 0.05 , the maximum number of correct outcomes for the other probabilistic models are 106, 105 and 117 on ED, ID and EI planes respectively. For improving the performance, we need to balance the number of false alarms and missed alarms, which is achieved by using RS threshold. The RS threshold has $F N$ numbers comparable with that of probabilistic rainfall thresholds, minimising the false alarms and by incorporating an additional filter using soil wetness, it reduces the number of false alarms when compared to the empirical ED threshold.

Table 2. Statistical attributes for quantitative comparison.

The probabilistic rainfall thresholds have high specificity values, pointing to their ability to correctly forecast the days without landslides, but with very less values of sensitivity. The points on ROC curves for probabilistic rainfall thresholds are therefore closer to both the axes, reducing the AUC. Even though the points have high specificity values, they are located far from the perfect point, due to their inefficiency in correctly forecasting the occurrence of landslides. The RS threshold with a critical probability of 0.1 is the closest one to the perfect point, correctly forecasting 167 landslide occurrences. 
From the analysis, the rainfall and soil wetness conditions for which the probability of occurrence is more than 0.1 should be considered critical. This makes it easier to identify the empirical ED threshold line for different values of soil wetness. The critical conditions are mentioned in Table 3.

Table 3. Critical conditions for initiation of landslides in Idukki, based on RS thresholds

From Table 3, it can be understood that when soil wetness is less than $0.2, \mathrm{~T}_{50}$ line of empirical ED thresholds should be considered as critical, when the soil wetness is between 0.2 to $0.4, \mathrm{~T}_{5}$ can be considered as the critical threshold. For the next two cases where soil wetness is between 0.4 to 0.8 , $\mathrm{T}_{10}$ threshold line can be considered as critical if the critical probability is 0.1 . In this case, the threshold line for 0.2 to 0.4 is $\mathrm{T}_{5}$, which is below the threshold line for soil wetness from 0.4 to 0.8 . This variation can be due to the smaller number of data points considered in this study. With the available data points, very less cases are reported when the soil wetness is between 0.4 to 0.8 , and the rainfall severity is below $\mathrm{T}_{10}$. To avoid any possible missed alarms due to the limitations of the dataset considered, the threshold for soil wetness between 0.4 to 0.8 is considered as $T_{1}$, for which the probability of occurrence of landslides is 0.05 in this study. This variation in the critical probability ensures the physical validity and easy export of the model. When the soil wetness is between 0.8 to 1 , even rainfall which is below $T_{1}$ can trigger landslides. Hence, for the last condition, we defined the critical case as $T_{\min }$ where $T_{\min }$ represents the threshold line with minimum exceedance probability, close to zero. Practically, it represents any possible rainfall condition.

The soil wetness data can be collected from daily satellite observations as taken in this study, or from real-time field observation using sensors. The severity of rainfall for each day can be estimated from the rainfall forecasts. Using these two inputs, the possibility of occurrence of landslide can be estimated using the conditions mentioned in Table 3. With higher exceedance probabilities, the relative uncertainty of $\alpha$ of ED threshold is crossing this limiting value. Similar results are observed when the rainfall data used is of daily temporal resolution (Teja et al., 2019). 
The type of landslides is also an important factor in identifying the associated rainfall. For example, rockfalls may be triggered without any rainfall, debris flows are often triggered by short duration (maybe less than 1 hour) and high intensity (Kean et al., 2011), and shallow landslides are triggered by short-term rainstorms of high-intensity or long-duration rainfall of low to medium intensity (Guzzetti et al., 2008). This is the main reason why the models (ED, and RS) often associated with the disadvantage of higher false alarms. Even though the false alarms are considerably reduced in RS thresholds, it needs further enhancements to be used in an LEWS. There are chances that the model may miss alarms for rockfalls, which can be triggered with no rainfall. In the case of flow like landslides such as debris flows, the failure can be triggered by very short, high intensity rainfalls. Such rainfall events may trigger landslides in relatively dry soils as well. In this case, even if the antecedent soil wetness is less than 0.2 , if the rainfall severity is greater than $\mathrm{T}_{50}$, the model will issue a warning. If an event of severity less than $\mathrm{T}_{50}$ triggers such an event, the model may miss the alarm. With a higher number of data points and better resolution of rainfall data, this can be improved, and better results can be expected.

\section{Conclusions}

This study has been conducted to evaluate the effect of antecedent soil moisture content to improving the performance of empirical and probabilistic thresholds for Idukki district in India. The district is suffering from landslides ranging from cut slope failures to debris flows during monsoon seasons. The recent disasters that happened in 2018 and 2019 in the district emphasises the requirement of a landslide early warning system for the region.

In this study, empirical rainfall thresholds on ED plane was derived for the study area using an algorithm-based approach. It was found that with 5\% exceedance probability, $20.19 \mathrm{~mm}$ rainfall can trigger a landslide in the region for a duration of 24 hours, and when the duration is 624 hours, a rainfall of $129 \mathrm{~mm}$ can trigger landslides in the region.

To evaluate the influence of each rainfall parameter on the occurrence of landslides, Bayesian analyses were conducted for both one-dimensional and two-dimensional cases. It was found that both 
intensity and event rainfall have influence on the occurrence of landslides, and most of the events

507 happened when the rainfall happened in lesser duration. From two-dimensional analysis, the

508 probabilities on EI plane were found to have the maximum values.

509 To evaluate the effect of soil wetness, another two-dimensional Bayesian approach was conducted,

510 and it was observed that when the soil is relatively dry, severe rainfall events are required to trigger

511 landslides and when the soil is wet, also milder rainfall conditions can trigger landslides in the study

512 area.

513 A statistical comparison between the considered models was used to find out the best performing

514 model. The comparison was carried out by using a ROC curve approach, where the RS threshold was

515 found to have the maximum AUC of 0.96, among the models considered in this study. The empirical

516 ED threshold generated a relevant number of false alarms, resulting in a low specificity value, while

517 the disadvantage associated with the probabilistic thresholds was the low sensitivity due to a large

518 number of missed alarms. The proposed method, which combines empirical thresholds with soil

519 wetness using a probabilistic approach, performs better than both the root models by optimising the

520 number of false alarms and missed alarms. Based on the comparison, it was found that an RS

521 threshold of probability 0.1 should be considered critical for the study area and critical rainfall

522 severity conditions were identified for each soil wetness condition. The performance could be further

523 enhanced in the future by using hourly rainfall data with more dense rain gauge network for the area.

524 Moreover, real-time monitoring of moisture content data for different locations in the study area can

525 also contribute to better resolution soil moisture data and thereby improving the performance of the

526 model. 
The results of the study therefore open new promising perspectives for the development of an operational LEWS in the Idukki district, by combining rainfall and soil moisture data. At the same time, this work provides evidences from a monsoon region about the advances brought by hydrometeorological thresholds based on soil moisture, which is gaining a growing attention in landslide studies all over the world but before today it was relatively unexplored for the setting of LEWS in the study area. Unfortunately, the use of soil moisture data in operational LEWS with short lead times is technically difficult, consequently another option to be explored is the use of antecedent rainfall conditions as a proxy to the soil moisture, which can be a simpler method to express the soil wetness conditions (Leonarduzzi and Molnar, 2020; Segoni et al., 2018b). More studies must be conducted for this region, to develop an effective LEWS which could obtain a fair compromise between the simplicity of the approach and the quality of the forecasting performance.

\section{Acknowledgements}

Analyses and visualizations used in this study were produced with the Giovanni online data system, developed and maintained by the NASA GES DISC. The research was supported by Università degli Studi di Firenze under the Grant 58517_INTERNAZIONALIZZAZIONE

\section{References}

Abraham, M.T., Pothuraju, D., Satyam, N., 2019. Rainfall Thresholds for Prediction of Landslides in Idukki, India: An Empirical Approach. Water 11, 2113. https://doi.org/10.3390/w11102113

Abraham, M.T., Satyam, N., Kushal, S., Rosi, A., Pradhan, B., Segoni, S., 2020a. Rainfall Threshold Estimation and Landslide Forecasting for Kalimpong, India Using SIGMA Model. Water 12, 1195. https://doi.org/10.3390/w12041195

Abraham, M.T., Satyam, N., Pradhan, B., Alamri, A.M., 2020b. Forecasting of landslides using rainfall severity and soil wetness: A probabilistic approach for Darjeeling Himalayas. Water (Switzerland) 12, 1-19. https://doi.org/10.3390/w12030804 
Abraham, M.T., Satyam, N., Pradhan, B., Alamri, A.M., 2020c. IoT-Based Geotechnical Monitoring of Unstable Slopes for Landslide Early Warning in the Darjeeling Himalayas. Sensors 20, 2611. https://doi.org/10.3390/s20092611

Abraham, M.T., Satyam, N., Reddy, S.K.P., Pradhan, B., 2020d. Runout modeling and calibration of friction parameters of Kurichermala debris flow, India. Landslides. https://doi.org/10.1007/s10346-020-01540-1

Abraham, M.T., Satyam, N., Rosi, A., Pradhan, B., Segoni, S., 2020e. The Selection of Rain Gauges and Rainfall Parameters in Estimating Intensity-Duration Thresholds for Landslide Occurrence: Case Study from Wayanad (India). Water 12, 1000. https://doi.org/10.3390/w12041000

Agostini, A., Tofani, V., Nolesini, T., Gigli, G., Tanteri, L., Rosi, A., Cardellini, S., Casagli, N., 2014. A new appraisal of the Ancona landslide based on geotechnical investigations and stability modelling. Q. J. Eng. Geol. Hydrogeol. 47, 29-43. https://doi.org/10.1144/qjegh2013-028

Aleotti, P., 2004. A warning system for rainfall-induced shallow failures. Eng. Geol. 73, 247-265. https://doi.org/10.1016/j.enggeo.2004.01.007

Alimohammadlou, Y., Najafi, A., Gokceoglu, C., 2014. Estimation of rainfall-induced landslides using ANN and fuzzy clustering methods: A case study in Saeen Slope, Azerbaijan province, Iran. Catena 120, 149-162. https://doi.org/10.1016/j.catena.2014.04.009

Althuwaynee, O.F., Pradhan, B., 2017. Semi-quantitative landslide risk assessment using GIS-based exposure analysis in Kuala Lumpur City. Geomatics, Nat. Hazards Risk 8, 706-732. https://doi.org/10.1080/19475705.2016.1255670

Althuwaynee, Omar, F., Pradhan, B., Ahmad, N., 2015. Estimation of rainfall threshold and its use in landslide hazard mapping of Kuala Lumpur metropolitan and surrounding areas. Landslides 12, $861-875$.

Alvioli, M., Melillo, M., Guzzetti, F., Rossi, M., Palazzi, E., von Hardenberg, J., Brunetti, M.T., Peruccacci, S., 2018. Implications of climate change on landslide hazard in Central Italy. Sci. 
Battistini, A., Rosi, A., Segoni, S., Lagomarsino, D., Catani, F., Casagli, N., 2017. Validation of landslide hazard models using a semantic engine on online news. Appl. Geogr. 82, 59-65. https://doi.org/10.1016/j.apgeog.2017.03.003

Baum, R.L., Savage, W.Z., Godt, J.W., 2008. TRIGRS - A Fortran Program for Transient Rainfall Infiltration and Grid-Based Regional Slope Stability Analysis.

Berti, M., Martina, M.L.V., Franceschini, S., Pignone, S., Simoni, A., Pizziolo, M., 2012. Probabilistic rainfall thresholds for landslide occurrence using a Bayesian approach. J. Geophys. Res. Earth Surf. 117, 1-20. https://doi.org/10.1029/2012JF002367

Bicocchi, G., Tofani, V., D’Ambrosio, M., Tacconi-Stefanelli, C., Vannocci, P., Casagli, N., Lavorini, G., Trevisani, M., Catani, F., 2019. Geotechnical and hydrological characterization of hillslope deposits for regional landslide prediction modeling. Bull. Eng. Geol. Environ. 78, 4875-4891. https://doi.org/10.1007/s10064-018-01449-z

Bogaard, T., Greco, R., 2018. Invited perspectives: Hydrological perspectives on precipitation intensity-duration thresholds for landslide initiation: Proposing hydro-meteorological thresholds. Nat. Hazards Earth Syst. Sci. 18, 31-39. https://doi.org/10.5194/nhess-18-31-2018

Brunetti, M.T., Peruccacci, S., Rossi, M., Luciani, S., Valigi, D., Guzzetti, F., 2010. Rainfall thresholds for the possible occurrence of landslides in Italy. Nat. Hazards Earth Syst. Sci. 10, 447-458. https://doi.org/10.5194/nhess-10-447-2010

Caine, N., 1980. The rainfall intensity-duration control of shallow landslides and debris flows: An update. Geogr. Ann. Ser. A, Phys. Geogr. 62, 1-2, 23-27.

CartoDEM, 2015. CartoDEM : a national digital elevation model from Cartosat-1 stereo data. Natl. Remote Sens. Centre, Hyderabad, Dep. Space, Gov. India.

Chae, B.G., Park, H.J., Catani, F., Simoni, A., Berti, M., 2017. Landslide prediction, monitoring and early warning: a concise review of state-of-the-art. Geosci. J. 21, 1033-1070. 
603 Chen, C.-W., Tung, Y.-S., Liou, J.-J., Li, H.-C., Cheng, C.-T., Chen, Y.-M., Oguchi, T., 2019. Assessing landslide characteristics in a changing climate in northern Taiwan. CATENA 175,

de Jeu, R. (Vrije U.A., Owe, M. (NASA G., 2014. AMSR2/GCOM-W1 surface soil moisture (LPRM) L3 1 day 25 km x 25 km descending V001, Edited by Goddard Earth Sciences Data and Information Services Center (GES DISC) (Bill Teng), Greenbelt, MD, USA, Goddard Earth Sciences Data and Information Services Cente. https://doi.org/10.5067/CGDEOBASZ178

de Jeu, R. (Vrije U.A., Owe, M. (NASA G., 2012. TMI/TRMM surface soil moisture (LPRM) L3 1

Department of Mining and Geology Kerala, 2016. District Survey Report of Minor Minerals.

Gadgil, M., Krishnan, B.J., Ganeshaiah, K.N., Vijayan., V.S., Borges, R., Sukumar, R., Noronha, L., Nayak, V.S., Subramaniam, D.K., Varma, R.V., Gautam, S.P., Navalgund, R.R., Subrahmanyam, G.V., 2011. Report of the Western Ghats Ecology Expert Panel (WGEEP). 
Gariano, S.L., Guzzetti, F., 2016. Landslides in a changing climate. Earth-Science Rev. 162, 227-252. https://doi.org/10.1016/j.earscirev.2016.08.011

Gariano, S.L., Melillo, M., Peruccacci, S., Brunetti, M.T., 2020. How much does the rainfall temporal resolution affect rainfall thresholds for landslide triggering? Nat. Hazards 100, 655-670. https://doi.org/10.1007/s11069-019-03830-x

Giovanni, 2020. NASA GES DISC [WWW Document].

Glade, T., Crozier, M., Smith, P., 2000. Applying probability determination to refine landslidetriggering rainfall thresholds using an empirical “Antecedent Daily Rainfall Model.” Pure Appl. Geophys. 157, 1059-1079. https://doi.org/10.1007/s000240050017

Guzzetti, F., Peruccacci, S., Rossi, M., Stark, C.P., 2008. The rainfall intensity-duration control of shallow landslides and debris flows: An update. Landslides 5, 3-17. https://doi.org/10.1007/s10346-007-0112-1

Guzzetti, F., Peruccacci, S., Rossi, M., Stark, C.P., 2007. Rainfall thresholds for the initiation of landslides in central and southern Europe. Meteorol. Atmos. Phys. 98, 239-267. https://doi.org/10.1007/s00703-007-0262-7

Iida, T., 1999. A stochastic hydro-geomorphological model for shallow landsliding due to rainstorm. Catena 34, 293-313. https://doi.org/10.1016/S0341-8162(98)00093-9

India Meteorlogical Department, 2019. India Meteorological Department (IMD) Data Supply Portal [WWW Document].

Iverson, R.M., 2000. Landslide triggering by rain infiltration. Water Resour. Res. 36, 1897-1910. https://doi.org/10.1029/2000WR900090

Jakob, M., Holm, K., Lange, O., Schwab, J.W., 2006. Hydrometeorological thresholds for landslide initiation and forest operation shutdowns on the north coast of British Columbia. Landslides 3, 228-238. https://doi.org/10.1007/s10346-006-0044-1 
Kean, J.W., Staley, D.M., Cannon, S.H., 2011. In situ measurements of post - fire debris flows in southern California : Comparisons of the timing and magnitude of 24 debris - flow events with rainfall and soil moisture conditions. J. Geophys. Res. 116, 1-21. https://doi.org/10.1029/2011JF002005

Keefer, D.K., Wilson, R.C., Mark, R.K., Brabb, E.E., Iii, W.M.B., Ellen, S.D., Harp, E.L., Wieczorek, G.F., Alger, C.S., Zatkint, R.S., 1987. Real-Time Landslide Warning During Heavy Rainfall. Science (80-. ). 238, 921-925.

Kim, M.S., Onda, Y., Uchida, T., Kim, J.K., Song, Y.S., 2018. Effect of seepage on shallow landslides in consideration of changes in topography: Case study including an experimental sandy slope with artificial rainfall. Catena 161, 50-62. https://doi.org/10.1016/j.catena.2017.10.004

Kirschbaum, D.B., Adler, R., Hong, Y., Kumar, S., Peters-Lidard, C., Lerner-Lam, A., 2012. Advances in landslide nowcasting: Evaluation of a global and regional modeling approach. Environ. Earth Sci. 66, 1683-1696. https://doi.org/10.1007/s12665-011-0990-3

Kuriakose, S.L., Devkota, S., Rossiter, D.G., Jetten, V.G., 2009a. Prediction of soil depth using environmental variables in an anthropogenic landscape, a case study in the Western Ghats of Kerala, India. Catena 79, 27-38. https://doi.org/10.1016/j.catena.2009.05.005

Kuriakose, S.L., Sankar, G., Muraleedharan, C., 2009b. History of landslide susceptibility and a chorology of landslide-prone areas in the Western Ghats of Kerala, India. Environ. Geol. 57, 1553-1568. https://doi.org/10.1007/s00254-008-1431-9

Lagomarsino, D., Segoni, S., Rosi, A., Rossi, G., Battistini, A., Catani, F., Casagli, N., 2015. Quantitative comparison between two different methodologies to define rainfall thresholds for landslide forecasting. Nat. Hazards Earth Syst. Sci. 15, 2413-2423. https://doi.org/10.5194/nhess-15-2413-2015

Lainas, S., Sabatakakis, N., Koukis, G., 2016. Rainfall thresholds for possible landslide initiation in 
Leonarduzzi, E., Molnar, P., 2020. Data limitations and potential of hourly and daily rainfall thresholds for shallow landslides. Nat. Hazards Earth Syst. Sci. Discuss. 1-25. https://doi.org/10.5194/nhess-2020-125

Marra, F., Destro, E., Nikolopoulos, E.I., Zoccatelli, D., Dominique Creutin, J., Guzzetti, F., Borga, M., 2017. Impact of rainfall spatial aggregation on the identification of debris flow occurrence thresholds. Hydrol. Earth Syst. Sci. 21, 4525-4532. https://doi.org/10.5194/hess-21-4525-2017

Melillo, M., Brunetti, M.T., Peruccacci, S., Gariano, S.L., Guzzetti, F., 2016. Rainfall thresholds for the possible landslide occurrence in Sicily (Southern Italy) based on the automatic reconstruction of rainfall events. Landslides 13, 165-172. https://doi.org/10.1007/s10346-015$0630-1$

Melillo, M., Brunetti, M.T., Peruccacci, S., Gariano, S.L., Guzzetti, F., 2014. An Algorithm for the objective reconstruction of rainfall events responsible for landslides. Landslide Dyn. ISDR-ICL Landslide Interact. Teach. Tools Vol. 1 Fundam. Mapp. Monit. 12, 311-320. https://doi.org/10.1007/978-3-319-57774-6_33

Melillo, M., Brunetti, M.T., Peruccacci, S., Gariano, S.L., Roccati, A., Guzzetti, F., 2018. A tool for the automatic calculation of rainfall thresholds for landslide occurrence. Environ. Model. Softw. 105, 230-243. https://doi.org/10.1016/j.envsoft.2018.03.024

Mirus, B.B., Becker, R.E., Baum, R.L., Smith, J.B., 2018a. Integrating real-time subsurface hydrologic monitoring with empirical rainfall thresholds to improve landslide early warning. Landslides 15, 1909-1919. https://doi.org/10.1007/s10346-018-0995-z

Mirus, B.B., Morphew, M.D., Smith, J.B., 2018b. Developing hydro-meteorological thresholds for shallow landslide initiation and early warning. Water (Switzerland) 10, 1-19. https://doi.org/10.3390/W10091274 
Nikolopoulos, E.I., Crema, S., Marchi, L., Marra, F., Guzzetti, F., Borga, M., 2014. Impact of uncertainty in rainfall estimation on the identification of rainfall thresholds for debris flow occurrence. Geomorphology 221, 286-297. https://doi.org/10.1016/j.geomorph.2014.06.015

Owe, M., de Jeu, R., Holmes, T., 2008. Multisensor historical climatology of satellite-derived global land surface moisture. J. Geophys. Res. Earth Surf. 113, 1-17. https://doi.org/10.1029/2007JF000769

Peruccacci, S., Brunetti, M.T., Gariano, S.L., Melillo, M., Rossi, M., Guzzetti, F., 2017. Rainfall thresholds for possible landslide occurrence in Italy. Geomorphology 290, 39-57. https://doi.org/10.1016/j.geomorph.2017.03.031

Peruccacci, S., Brunetti, M.T., Luciani, S., Vennari, C., Guzzetti, F., 2012. Lithological and seasonal control on rainfall thresholds for the possible initiation of landslides in central Italy. Geomorphology 139-140, 79-90. https://doi.org/10.1016/j.geomorph.2011.10.005

Piciullo, L., Calvello, M., Cepeda, J.M., 2018. Territorial early warning systems for rainfall-induced landslides. Earth-Science Rev. 179, 228-247. https://doi.org/10.1016/j.earscirev.2018.02.013

Ponziani, F., Pandolfo, C., Stelluti, M., Berni, N., Brocca, L., Moramarco, T., 2012. Assessment of rainfall thresholds and soil moisture modeling for operational hydrogeological risk prevention in the Umbria region (central Italy). Landslides 9, 229-237. https://doi.org/10.1007/s10346-011$0287-3$

Sajeev, R., Praveen, K.R., 2014. Landslide Susceptibility Mapping on Macroscale along the Major Road Corridors in Idukki District, Kerala. Thiruvananthapuram, India.

Segoni, S., Piciullo, L., Gariano, S.L., 2018a. A review of the recent literature on rainfall thresholds for landslide occurrence. Landslides 15, 1483-1501. https://doi.org/10.1007/s10346-018-0966-4

Segoni, S., Rosi, A., Fanti, R., Gallucci, A., Monni, A., Casagli, N., 2018b. A regional-scale landslide warning system based on 20 years of operational experience. Water (Switzerland) 10, 1-17. https://doi.org/10.3390/w10101297 
Segoni, S., Rosi, A., Lagomarsino, D., Fanti, R., Casagli, N., 2018c. Brief communication: Using averaged soil moisture estimates to improve the performances of a regional-scale landslide early warning system. Nat. Hazards Earth Syst. Sci. 18, 807-812. https://doi.org/10.5194/nhess-18$807-2018$

Song, S., Wang, W., 2019. Impacts of antecedent soil moisture on the rainfall- runoff transformation process based on high- resolution observations in soil tank experiments. Water (Switzerland) 11, 15-20. https://doi.org/10.3390/w11020296

Teja, T.S., Dikshit, A., Satyam, N., 2019. Determination of rainfall thresholds for landslide prediction using an algorithm-based approach: Case study in the Darjeeling Himalayas, India. Geosci. 9. https://doi.org/10.3390/geosciences9070302

Terlien, M.T.J., 1998. The determination of statistical and deterministic hydrological landslidetriggering thresholds. Environ. Geol. 35, 124-130. https://doi.org/10.1007/s002540050299

Tofani, V., Bicocchi, G., Rossi, G., Segoni, S., D’Ambrosio, M., Casagli, N., Catani, F., 2017. Soil characterization for shallow landslides modeling: a case study in the Northern Apennines (Central Italy). Landslides 14, 755-770. https://doi.org/10.1007/s10346-017-0809-8

Uchimura, T., Towhata, I., Anh, T.T.L., Fukuda, J., Bautista, C.J.B., Wang, L., Seko, I., Uchida, T., Matsuoka, A., Ito, Y., Onda, Y., Iwagami, S., Kim, M.S., Sakai, N., 2010. Simple monitoring method for precaution of landslides watching tilting and water contents on slopes surface. Landslides 7, 351-357. https://doi.org/10.1007/s10346-009-0178-z

Uchimura, T., Towhata, I., Wang, L., Nishie, S., Yamaguchi, H., Seko, I., Qiao, J., 2015. Precaution and early warning of surface failure of slopes using tilt sensors. Soils Found. 55, 1086-1099. https://doi.org/10.1016/j.sandf.2015.09.010

United Nations Development Programme, 2018. Kerala Post Disaster Needs Assessment Floods and Landslides-August 2018. Thiruvananthapuram, India.

Valenzuela, P., Domínguez-Cuesta, M.J., Mora García, M.A., Jiménez-Sánchez, M., 2018. Rainfall 
thresholds for the triggering of landslides considering previous soil moisture conditions (Asturias, NW Spain). Landslides 15, 273-282. https://doi.org/10.1007/s10346-017-0878-8

Varnes, D., 1978. Slope Movement Types and Processes. Transp. Res. Board Spec. Rep.

Wei, X., Fan, W., Cao, Y., Chai, X., Bordoni, M., Meisina, C., Li, J., 2020. Integrated experiments on field monitoring and hydro-mechanical modeling for determination of a triggering threshold of rainfall-induced shallow landslides. A case study in Ren River catchment, China. Bull. Eng. Geol. Environ. 79, 513-532. https://doi.org/10.1007/s10064-019-01570-7

Wicki, A., Lehmann, P., Hauck, C., Seneviratne, S.I., Waldner, P., Stähli, M., 2020. Assessing the potential of soil moisture measurements for regional landslide early warning. Landslides 17, 1881-1896. https://doi.org/10.1007/s10346-020-01400-y

Wu, M.H., Wang, J.P., Chen, I.C., 2019. Optimization approach for determining rainfall durationintensity thresholds for debris flow forecasting. Bull. Eng. Geol. Environ. 78, 2495-2501. https://doi.org/10.1007/s10064-018-1314-6

Yang, Z., Cai, H., Shao, W., Huang, D., Uchimura, T., Lei, X., Tian, H., Qiao, J., 2019. Clarifying the hydrological mechanisms and thresholds for rainfall-induced landslide: in situ monitoring of big data to unsaturated slope stability analysis. Bull. Eng. Geol. Environ. 78, 2139-2150. https://doi.org/10.1007/s10064-018-1295-5

Zhao, B., Dai, Q., Han, D., Dai, H., Mao, J., Zhuo, L., 2019a. Probabilistic thresholds for landslides warning by integrating soil moisture conditions with rainfall thresholds. J. Hydrol. 574, 276287. https://doi.org/10.1016/j.jhydrol.2019.04.062

Zhao, B., Dai, Q., Han, D., Dai, H., Mao, J., Zhuo, L., Rong, G., 2019b. Estimation of soil moisture using modified antecedent precipitation index with application in landslide predictions. Landslides 16, 2381-2393. https://doi.org/10.1007/s10346-019-01255-y 


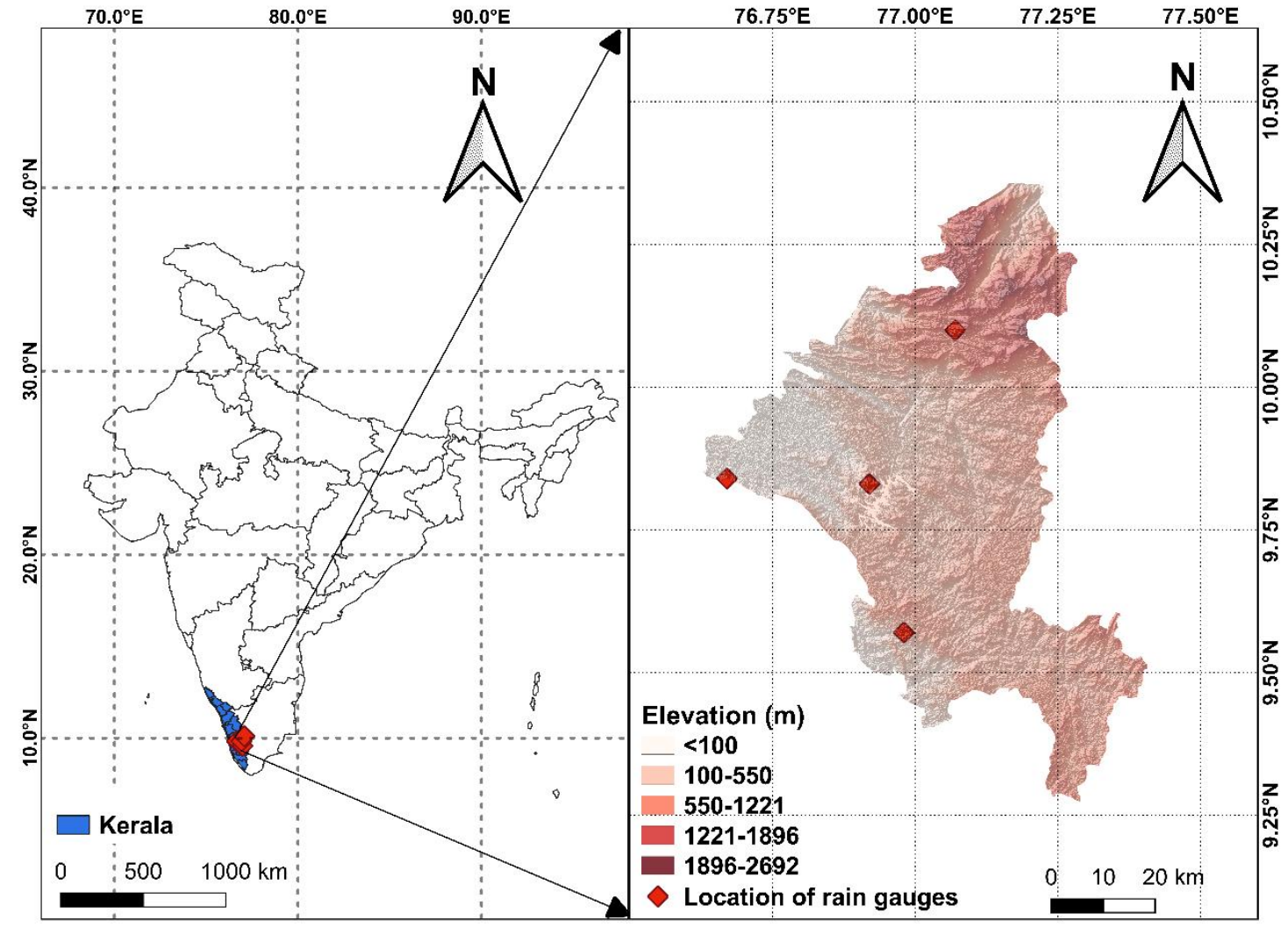

Fig. 1. Location details of study area. (a) India, and (b) Digital Elevation Model of Idukki (modified using CartoDEM (CartoDEM, 2015)) along with location of rain gauges. 


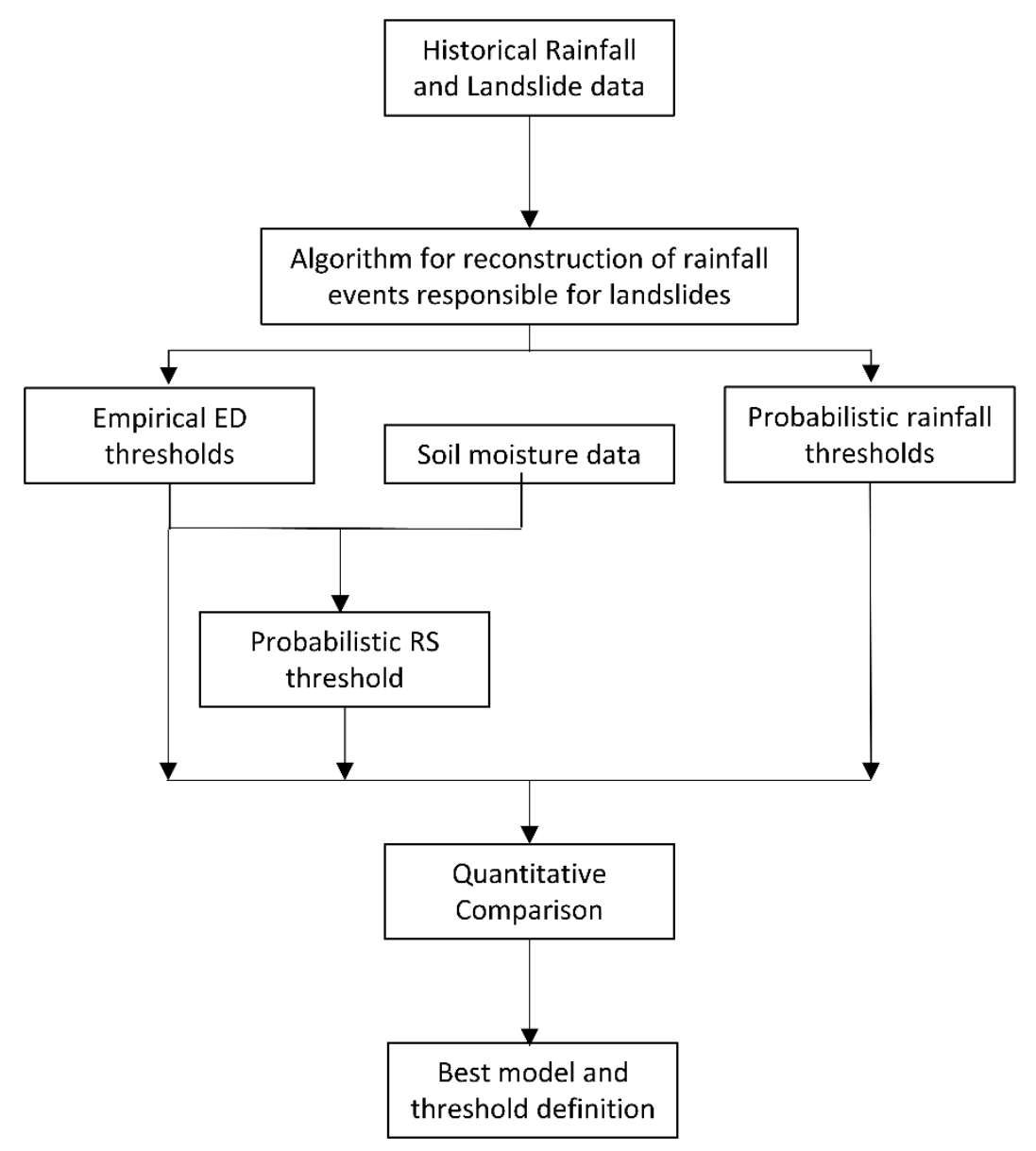

Fig. 2. Methodology of study. 


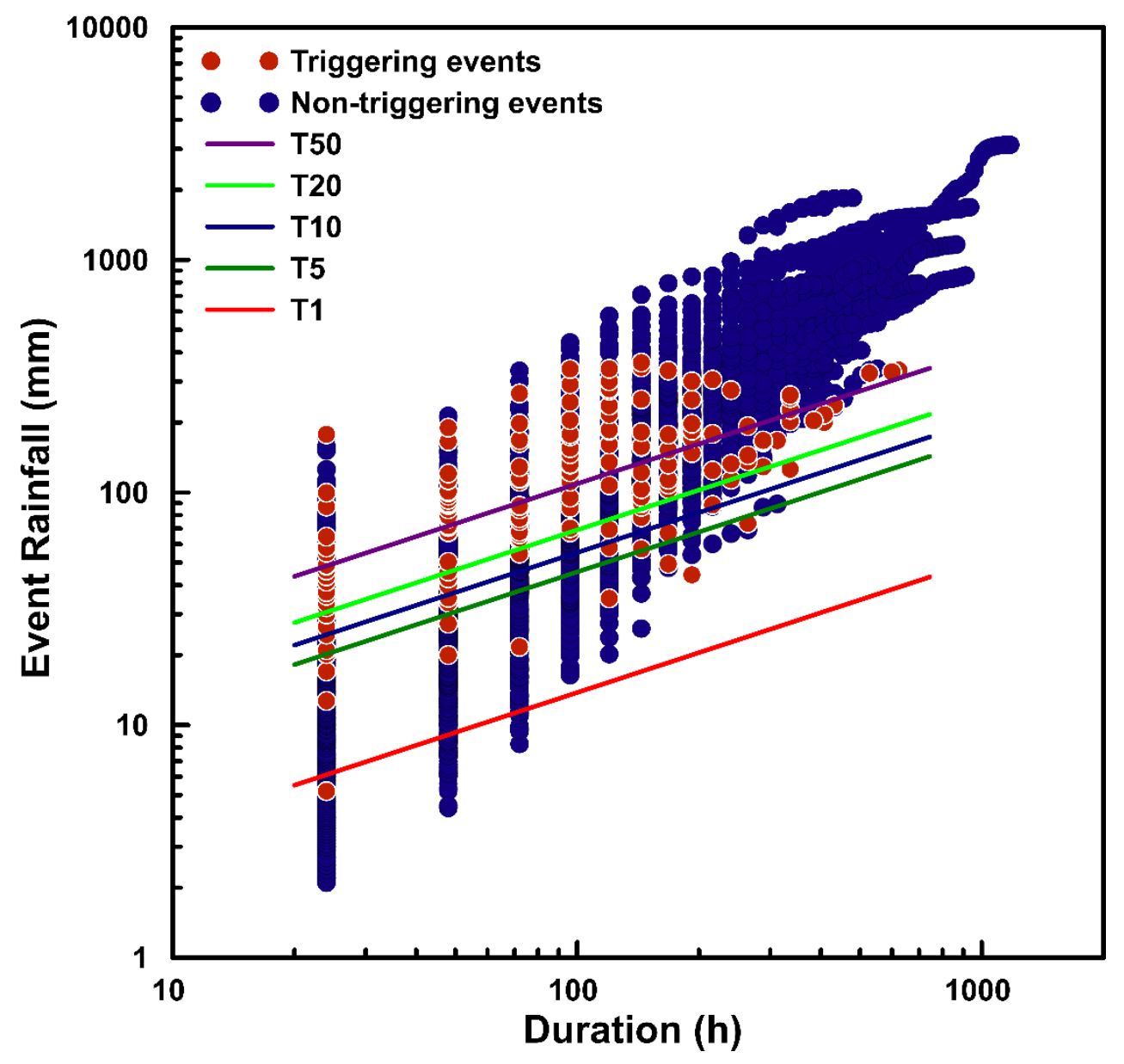

Fig. 3. Rainfall event - duration thresholds for Idukki district. 

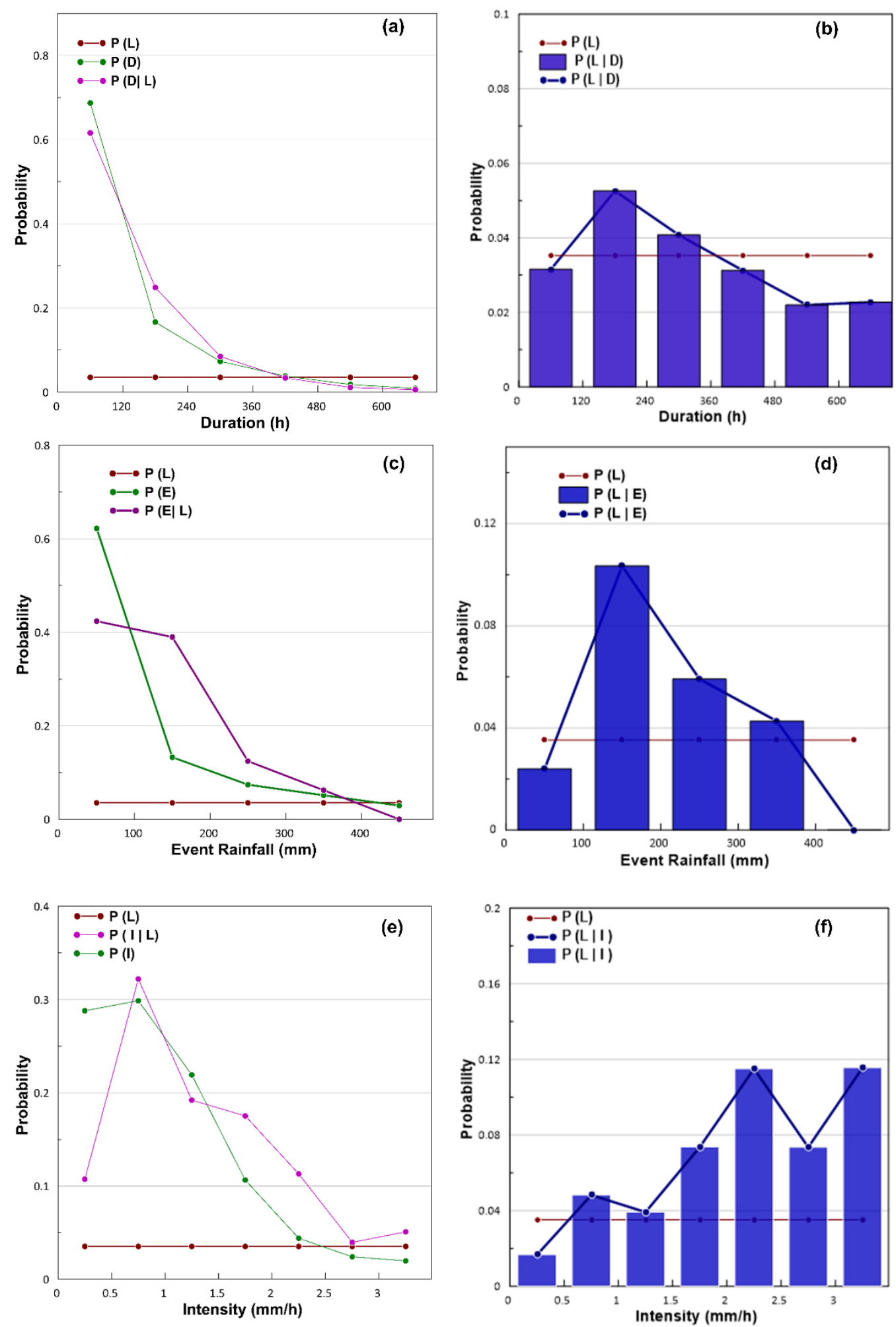

Fig. 4. Prior, conditional, marginal and posterior probabilities with respect to rainfall parameters. (a, b) Duration; (c, d) Event rainfall; and (e, f) Intensity. 

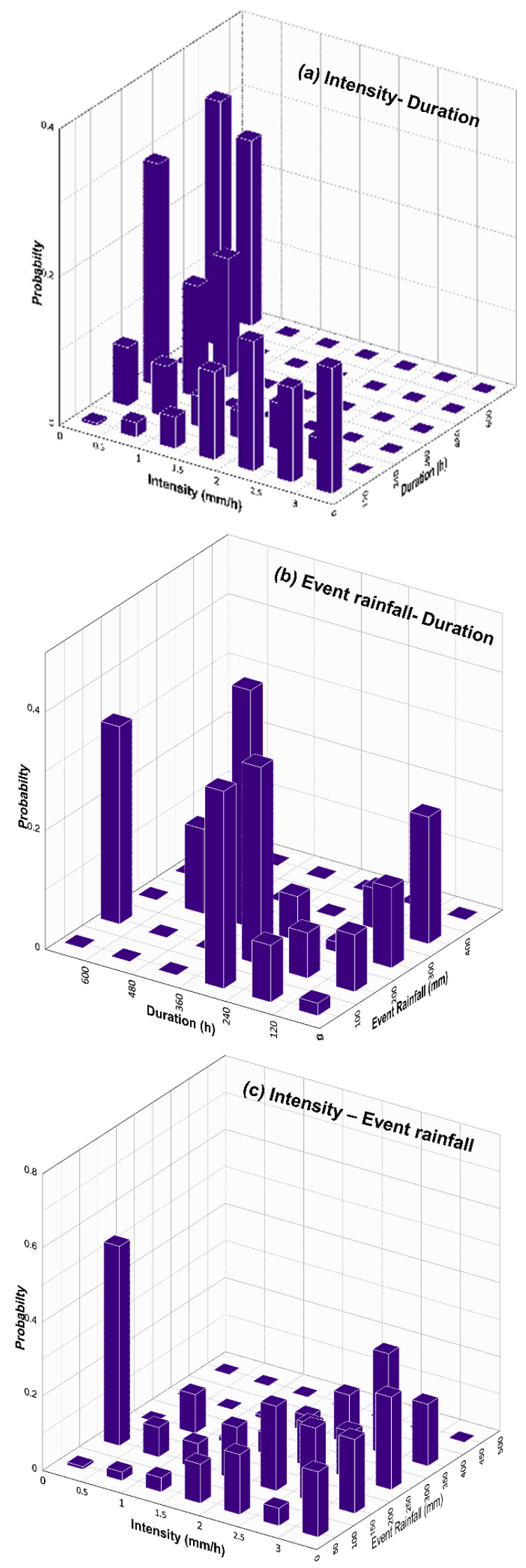

Fig. 5. Two-dimensional posterior probabilities of occurrence of landslide on (a) ID plane, (b) ED plane, and (c) EI plane. 


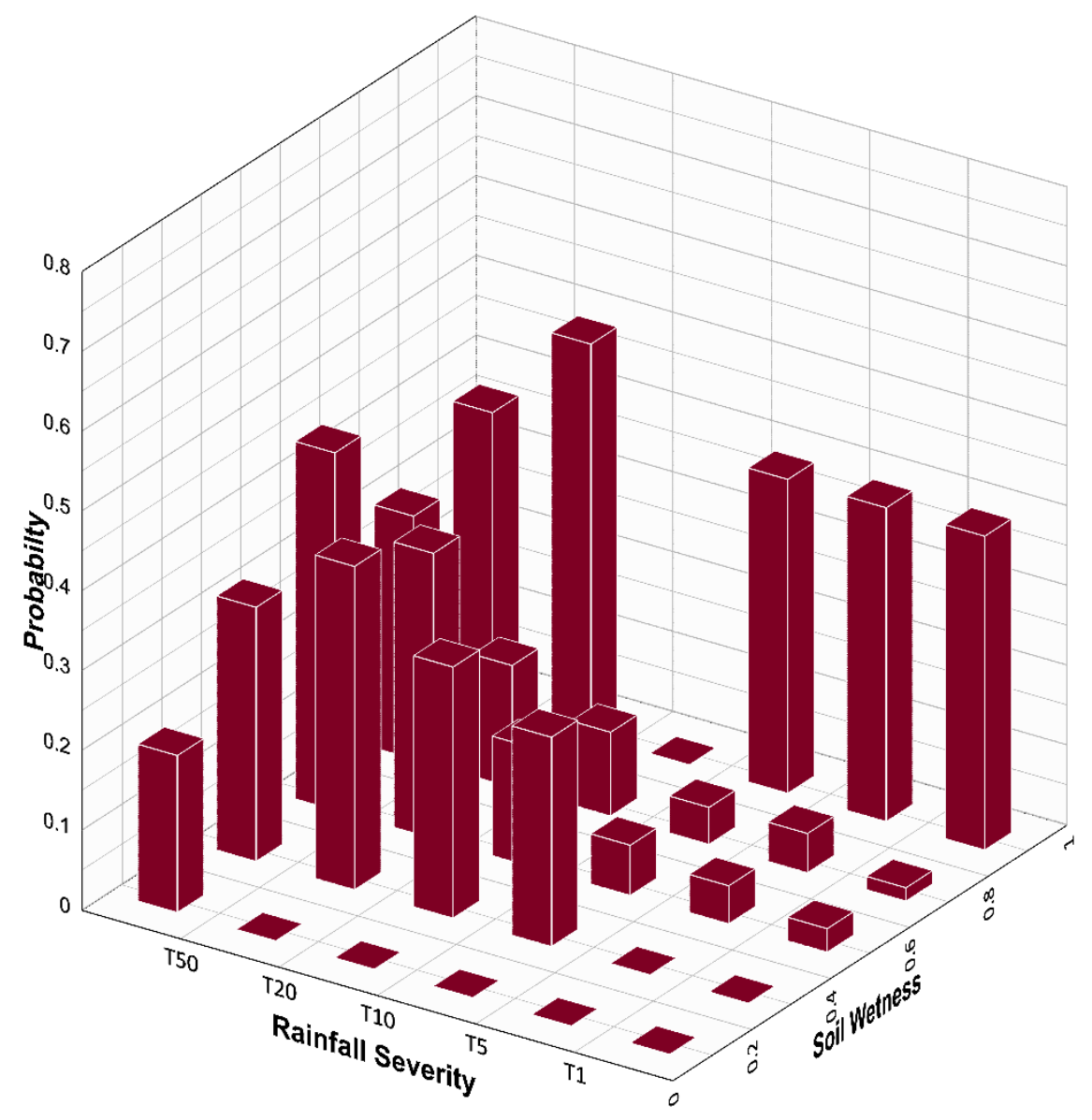

Fig. 6. Two dimensional Bayesian probabilities for occurrence of landslides based on rainfall severity and soil wetness. 


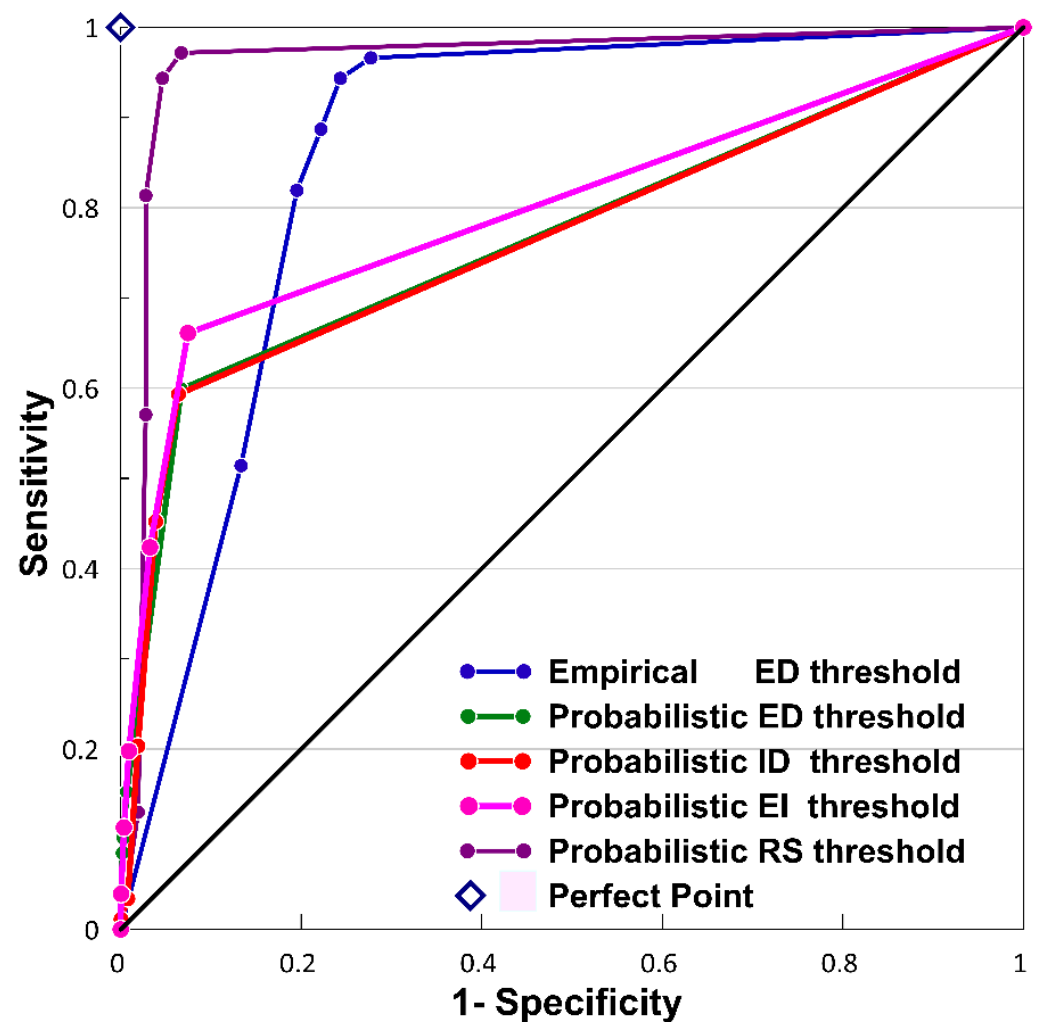

Fig. 7. ROC curves for the derived thresholds. Sensitivity is the ability of a model to correctly identify the landslide events and Specificity is the ability to correctly identify the non-landslide events 


\section{Figure captions}

Fig. 1. Location details of study area. (a) India, and (b) Digital Elevation Model of Idukki (modified using CartoDEM (National Remote Sensing Centre 2015)) along with location of rain gauges.

Fig. 2. Methodology of study.

Fig. 3. Rainfall event - duration thresholds for Idukki district.

Fig. 4. Prior, conditional, marginal and posterior probabilities with respect to rainfall parameters. (a, b) Duration; (c, d) Event rainfall; and (e, f) Intensity.

Fig. 5. Two-dimensional posterior probabilities of occurrence of landslide on (a) ID plane, (b) ED plane, and (c) EI plane.

Fig. 6. Two dimensional Bayesian probabilities for occurrence of landslides based on rainfall severity and soil wetness.

Fig. 7. ROC curves for the derived thresholds. Sensitivity is the ability of a model to correctly identify the landslide events and Specificity is the ability to correctly identify the non-landslide events 
Click here to download Table: Tables_revision R2_22oct2020.docx

Table 1. Values of $\alpha, \gamma$ and the uncertainties associated with different exceedance probabilities

\begin{tabular}{ccccc}
\hline Threshold & $\boldsymbol{\alpha}$ & $\boldsymbol{\Delta \alpha}$ & $\boldsymbol{\gamma}$ & $\boldsymbol{\Delta} \boldsymbol{\gamma}$ \\
\hline $\mathrm{T}_{1}$ & 2.3 & 0.8 & 0.57 & 0.03 \\
$\mathrm{~T}_{5}$ & 3.3 & 1.1 & 0.57 & 0.03 \\
$\mathrm{~T}_{10}$ & 4.0 & 1.3 & 0.57 & 0.03 \\
$\mathrm{~T}_{20}$ & 5.0 & 1.6 & 0.57 & 0.03 \\
$\mathrm{~T}_{50}$ & 7.9 & 2.4 & 0.57 & 0.03 \\
\hline
\end{tabular}


Table 2. Statistical attributes for quantitative comparison.

\begin{tabular}{|c|c|c|c|c|c|c|c|c|c|c|c|}
\hline \multirow[b]{2}{*}{$\begin{array}{c}\text { Thresh } \\
\text { old } \\
\text { model }\end{array}$} & \multirow[b]{2}{*}{$\begin{array}{c}\text { Threshold } \\
\text { value }\end{array}$} & \multirow[b]{2}{*}{$\mathbf{T P}$} & \multirow[b]{2}{*}{ FP } & \multirow[b]{2}{*}{ FN } & \multirow[b]{2}{*}{$\mathbf{T N}$} & \multirow[b]{2}{*}{$\begin{array}{l}\text { Sensi } \\
\text { tivity }\end{array}$} & \multirow[b]{2}{*}{$\begin{array}{l}\text { Speci } \\
\text { ficity }\end{array}$} & \multicolumn{3}{|l|}{ Distance } & \multirow[b]{2}{*}{ AUC } \\
\hline & & & & & & & & $\begin{array}{c}\text { from } \\
\text { perfect } \\
\text { point }\end{array}$ & $\begin{array}{c}\text { Thre } \\
\text { at } \\
\text { score }\end{array}$ & $\begin{array}{c}\text { True } \\
\text { skill } \\
\text { statistic }\end{array}$ & \\
\hline \multirow{5}{*}{$\begin{array}{c}\text { Empiric } \\
\text { al ED }\end{array}$} & $\mathrm{T} 1$ & 171 & 3594 & 6 & 9377 & 0.97 & 0.72 & 0.28 & 0.05 & 0.69 & \multirow{5}{*}{0.86} \\
\hline & T5 & 167 & 3156 & 10 & 9815 & 0.94 & 0.76 & 0.25 & 0.05 & 0.70 & \\
\hline & $\mathrm{T} 10$ & 157 & 2878 & 20 & 10093 & 0.89 & 0.78 & 0.25 & 0.05 & 0.67 & \\
\hline & $\mathrm{T} 20$ & 145 & 2531 & 32 & 10440 & 0.82 & 0.80 & 0.27 & 0.05 & 0.62 & \\
\hline & T50 & 91 & 1729 & 86 & 11242 & 0.51 & 0.87 & 0.50 & 0.05 & 0.38 & \\
\hline \multirow{5}{*}{$\begin{array}{l}\text { Probabil } \\
\text { istic ED }\end{array}$} & 0.05 & 106 & 870 & 71 & 12101 & 0.60 & 0.93 & 0.41 & 0.10 & 0.53 & \multirow{5}{*}{0.77} \\
\hline & 0.1 & 27 & 86 & 150 & 12885 & 0.15 & 0.99 & 0.85 & 0.10 & 0.15 & \\
\hline & 0.15 & 18 & 36 & 159 & 12935 & 0.10 & 1.00 & 0.90 & 0.08 & 0.10 & \\
\hline & 0.2 & 18 & 36 & 159 & 12935 & 0.10 & 1.00 & 0.90 & 0.08 & 0.10 & \\
\hline & 0.3 & 15 & 25 & 162 & 12946 & 0.08 & 1.00 & 0.92 & 0.07 & 0.08 & \\
\hline \multirow{5}{*}{$\begin{array}{l}\text { Probabil } \\
\text { istic ID }\end{array}$} & 0.05 & 105 & 830 & 72 & 12141 & 0.59 & 0.94 & 0.41 & 0.10 & 0.53 & \multirow{5}{*}{0.77} \\
\hline & 0.1 & 80 & 502 & 97 & 12469 & 0.45 & 0.96 & 0.55 & 0.12 & 0.41 & \\
\hline & 0.15 & 36 & 247 & 141 & 12724 & 0.20 & 0.98 & 0.80 & 0.08 & 0.18 & \\
\hline & 0.2 & 6 & 102 & 171 & 12869 & 0.03 & 0.99 & 0.97 & 0.02 & 0.03 & \\
\hline & 0.3 & 2 & 6 & 175 & 12965 & 0.01 & 1.00 & 0.99 & 0.01 & 0.01 & \\
\hline \multirow{5}{*}{$\begin{array}{l}\text { Probabil } \\
\text { istic EI }\end{array}$} & 0.05 & 117 & 966 & 60 & 12005 & 0.66 & 0.93 & 0.35 & 0.10 & 0.59 & \multirow{5}{*}{0.79} \\
\hline & 0.1 & 75 & 421 & 102 & 12550 & 0.42 & 0.97 & 0.58 & 0.13 & 0.39 & \\
\hline & 0.15 & 35 & 117 & 142 & 12854 & 0.20 & 0.99 & 0.80 & 0.12 & 0.19 & \\
\hline & 0.2 & 20 & 47 & 157 & 12924 & 0.11 & 1.00 & 0.89 & 0.09 & 0.11 & \\
\hline & 0.3 & 7 & 6 & 170 & 12965 & 0.04 & 1.00 & 0.96 & 0.04 & 0.04 & \\
\hline \multirow{5}{*}{$\begin{array}{l}\text { Probabil } \\
\text { istic RS }\end{array}$} & 0.05 & 172 & 3133 & 5 & 9838 & 0.97 & 0.76 & 0.24 & 0.05 & 0.73 & \multirow{5}{*}{0.96} \\
\hline & 0.1 & 167 & 527 & 10 & 12444 & 0.94 & 0.96 & 0.07 & 0.24 & 0.90 & \\
\hline & 0.15 & 144 & 477 & 33 & 12494 & 0.81 & 0.96 & 0.19 & 0.22 & 0.78 & \\
\hline & 0.2 & 101 & 470 & 76 & 12501 & 0.57 & 0.96 & 0.43 & 0.16 & 0.53 & \\
\hline & 0.3 & 23 & 98 & 154 & 12873 & 0.13 & 0.99 & 0.87 & 0.08 & 0.12 & \\
\hline
\end{tabular}


Table 3. Critical conditions for initiation of landslides in Idukki, based on RS thresholds.

\begin{tabular}{cc}
\hline Soil Wetness & Critical ED threshold line \\
\hline $0.0-0.2$ & $\mathrm{~T}_{50}$ \\
$0.2-0.4$ & $\mathrm{~T}_{5}$ \\
$0.4-0.6$ & $\mathrm{~T}_{10} \underline{\mathrm{T}}_{1}$ \\
$0.6-0.8$ & $\mathrm{~F}_{10} \mathrm{~T}_{1}$ \\
$0.8-1.0$ & $\mathrm{~T}_{\min }$ \\
\hline
\end{tabular}




\section{Declaration of interests}

$\bigotimes$ The authors declare that they have no known competing financial interests or personal relationships that could have appeared to influence the work reported in this paper.

$\square$ The authors declare the following financial interests/personal relationships which may be considered as potential competing interests:

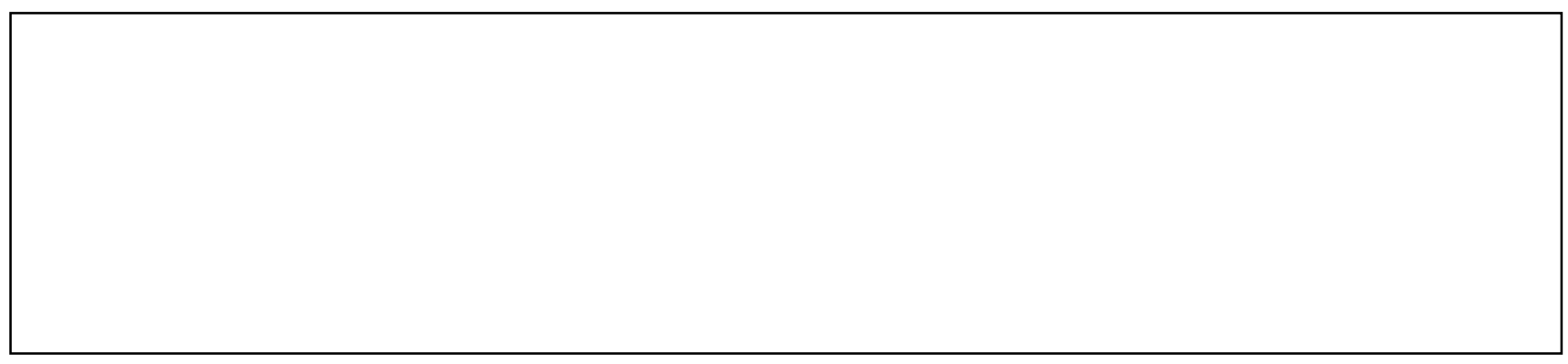

